\title{
Prosody-Syntax Interaction in the Expression of Focus
}

\author{
Vieri Samek-Lodovici
}

\begin{abstract}
Prosodic and syntactic constraints conflict with each other. This is particularly evident in the expression of focus, where the best position for main stress does not necessarily match the best syntactic position for the focused constituent. But focus and stress must match, therefore either stress or the focused constituent must renounce their best position violating either the syntactic or the prosodic constraints responsible for them.

This study argues that human language addresses this tension in optimality theoretic terms and that different focus paradigms across different languages reflect different rankings of a shared invariant set of syntactic and prosodic constraints. In particular, only an optimality analysis can account for the focus paradigm of Italian while keeping a prosodic analysis of main stress in accord with the last two decades of phonological research. The analysis extends naturally to focus paradigms in English, French, and Chichewa (including Chichewa's non-culminant sentences, i.e. sentences lacking a single main stress), making no appeal to language specific parametric devices.

Overall, the conflicting nature of prosodic and syntactic constraints gives rise to a complex crosslinguistic typology from a single set of universal constraints while keeping interface conditions to an absolute minimum.
\end{abstract}

\section{Introduction}

Constraints on prosodic and syntactic well-formedness make conflicting demands on linguistic structures. The conflict emerges most clearly when considering the expression of new information focus in Italian and English. In focus-neutral contexts, both languages assign stress rightmost and share a head-initial SVO syntactic layout. This canonical pattern occurs when focus affects the entire clause, as when answering a question like 'what happened?'. An example follows in (1) below with focus marked as ' $\mathrm{f}$ ' and main stress in capital.
(1)
a. English: [ John has LAUGHED $]_{\mathrm{f}}$
Context: What happened?
b. Italian:
[ Gianni ha RISO ]
Context: What happened?

The conflict between prosody and syntax is unleashed whenever focus is restricted to a nonfinal constituent in the clause. The condition that focus be stressed requires that the focused constituent and main stress be matched with each other, forcing one or the other to abandon their canonical position. For example, when the subject is focused, either the subject preserves its canonical syntactic position and stress shifts leftwards, as in the English example in (2) below, or main stress preserves its canonical rightmost prosodic position and the subject occurs clause finally, as in the Italian sentence in (3).

English: $\quad \mathrm{JOHN}_{\mathrm{f}}$ has laughed

Context: Who has laughed?

*This work was made possible by a Research Leave grant awarded by the Arts and Humanities Research Board (AHRB, UK). It immensely profited from discussions with Valentina Bianchi, Daniel Büring, Peter Culicover, Laura Downing, Caroline Fery, Mirco Ghini, Jane Grimshaw, Robert Ladd, Aditi Lahiri, Alan Prince, Ken Safir, Hubert Truckenbrodt and Sten Vikner. Special thanks for comments and insights are also due to Peter Ackema, Philippa Cook, Gisbert Fanselow, Caroline Heycock, Hans-Martin Gartner, Geraldine Legendre, Ad Neeleman, Paul Smolensky, Antonella Sorace, Sabine Zerbian, as well as audiences at Rutgers University, ZAS Berlin, University of Potsdam, University College London, University of Edinburgh, SOAS (London), University of Stuttgart, University of Frankfürt, CUNY, Universitá di Venezia and Universitá per Stranieri di Siena. I am also very grateful to my informants Birgit Alber, Isabelle Barriere, Cecile De Cat, lisabeth Kley, Geraldine Legendre, Aditi Lahiri, Elisa Marroni, Sophie Mesplede, Phaedra Royle, Hubert Truckenbrodt, Roberto Zamparelli. 
This simple paradigm and the associated conflict, also noted in Zubizarreta (1994, 1998), Lambrecht (1994), Vallduví (1991, 1992) and Engdahl \& Vallduví (1994), call for an explanation of why grammars that clearly obey the same constraints of prosodic and syntactic organization under sentence-wide focus contexts turn out to violate those very same constraints when focusing specific constituents. We also need to understand why they do so in perfectly opposite ways as if choosing which constraints to uphold and which to violate.

\subsection{Earlier Analyses and Open Issues}

Many of the earlier analyses of focus concentrate only on its prosodic or its syntactic properties in specific languages. For example, following the seminal studies on structural focus by Kiss (1981), Horvath (1986), Rochemont (1986), Rochemont and Culicover (1990), and Brody (1990), clause-final focus in Italian and other Romance languages has been viewed by many scholars as involving a dedicated focus position or projection (see Antinucci \& Cinque 1977, Calabrese 1982, 1986, 1992, Bonet 1990, Vallduví 1992, Saccon 1993, Belletti and Shlonsky 1995, Samek-Lodovici 1996a). These analyses provide many valid insights but do not explain why focus occurs clause finally rather than elsewhere. The position of focus remains stipulated.

A crucial step forward is accomplished by Zubizarreta's research on the relation between focus and prosody $(1994,1998)$ and in similar studies by Reinhart (1995) and Cinque (1993). Zubizarreta ties the position of clause-final focus in Romance to the position of main stress: focused phrases occur rightmost rather than in their canonical syntactic position because focus needs stress and stress in these languages is rightmost. Zubizarreta thus places the interaction between prosody and syntax and their conflicting demands at the very core of Romance focus.

Zubizarreta's insights raise some important issues. First of all, we need to understand how exactly prosodic constraints on stress can cause syntactic movement. Conversely, we should consider whether syntactic constraints can themselves affect the position of stress, as suggested by the above English data. More generally, since prosodic and syntactic constraints conflict with each other, we need a theory of conflict resolution. This theory must explain why structures (2) and (3) above, which clearly violate the constraints responsible for rightmost stress and SVO order in the canonical clauses in (1), become nevertheless grammatical when the subject is focused. Does conflict resolution force grammaticality under constraint violation and if so what is the analysis of it?

These issues receive very different answers depending on the theoretical framework under which they are examined. In this respect, important aspects of the analysis proposed in Zubizarreta (1998) appear dictated by the adoption of a minimalist perspective. In particular, under minimalism phonological structuring logically follows overt syntax, making the position of stress inaccessible to syntax. Yet as Zubizarreta (1998) convincingly argued, in Romance clausefinal focus syntax accesses the position of stress to ensure that focus matches it. To solve this paradox, Zubizarreta is forced to define stress in purely syntactic terms, so that its position can be determined prior to overt syntactic movement. The cost is a radical dissociation of main stress from prosodic structuring against a wealth of well established studies tying stress to prosodic constituency (see among others Prince 1983, Selkirk 1984 1986, 1995, Nespor 1990, Nespor \& Vogel 1986, 1989, Halle \& Vergnaud 1987, Ghini 1993, McCarthy \& Prince 1993, Hayes 1995, Deevy 1995, Truckenbrodt 1995, 1999). 
Minimalism also disallows constraint conflicts and therefore has no principled way to detect them. For this reason, Zubizarreta is obliged to introduce a device in the grammar of Italian that detects the mismatch between the positions of stress and focus (Zubizarreta, 1998:139-140). This device requires a structural representation of the mismatch in its definition which is equivalent to equipping grammar with meta-knowledge about the structures that will emerge from its assembling operations. Once a principled theory of constraint conflict is in place such devices become unnecessary.

The absence of a theory of constraint conflict also prevents Zubizarreta from considering the full range of possible resolutions for the conflict that she identified. In particular, it prevented her from recognizing that the Italian and English focus patterns constitute symmetric solutions of the same conflict among the same constraints in both languages. Her analysis, instead, is forced to capture the differences between the two languages via language-specific parameters. These too become unnecessary once a theory of constraint conflict is in place.

\subsection{An OT-approach to Prosody-Syntax interaction}

Reanalyzing Zubizarreta's core insights in the context of a principled theory of constraint conflict like Optimality Theory (Prince \& Smolensky 1993) provides us with a model of the prosody-syntax interface free of the problematic aspects mentioned above and covering a wide set of focus paradigms. Under optimality theory universal well-formedness constraints may conflict with each other. The grammar of each language corresponds to a specific ranking of the conflicting constraints. Conflicts are resolved in a principled fashion with lower ranked constraints yielding to higher ones. Therefore different rankings of the same constraints determine different conflict resolutions, giving rise to crosslinguistic variation. ${ }^{1}$

The conflict between syntax and prosody is inherent to the universal constraints on prosodic and syntactic representations identified in the last two decades of linguistic research. With respect to prosody, I will consider the constraints in Truckenbrodt $(1995,1999)$ governing prosodic structure and eventually favoring rightmost main stress as a side-effect (see also Prince 1983, Selkirk 1984, 1986, 1995. Nespor \& Vogel 1986, Halle \& Vergnaud 1987, Hayes 1995).

These constraints conflict with the syntactic constraints EPP and Stay (Grimshaw 1993, 1997) which disfavor divergence from the $\langle\mathrm{S} \mathrm{V} \mathrm{O} \mathrm{IO}\rangle$ canonical order of the languages examined here. In Italian, high-ranked prosodic constraints force stress rightmost even when this violates EPP and Stay, giving rise to clause-final focus. In English, where EPP and Stay are not dominated by prosodic constraints, the canonical syntactic order is preserved at the cost of prosodic wellformedness, with stress abandoning the favored rightmost position to match the position of focused constituents.

1 Non OT-practitioners will be able to follow the analysis through the explanations provided throughout the paper. For the interested readers, a simple algorithm for assessing grammaticality under constraint ranking is provided below (adapted from Prince \& Smolensky 1993).

(i) A grammar is identified by a ranking of the universal constraints of UG.

(ii) Grammaticality is defined relative to a constraint ranking in the following way:

- Different linguistic structures compete for grammatical status under the given ranking.

- For any two structures, let $\mathrm{C}$ be the highest constraint not violated an equal number of times by both structures, then the structure violating $\mathrm{C}$ the least eliminates the other.

- The best available structure, i.e. the one that eliminates all other competitors, is optimal and attains grammatical status under the ranking at hand. All other structures are ungrammatical. 
As we will examine in detail in $\$ 5$, a syntactic analysis of stress becomes unnecessary because syntactic and prosodic constraints simultaneously assess all possible combinations of syntactic and prosodic representations. The combination that best satisfies a given constraint ranking is grammatical under the corresponding language. The analysis of stress thus remains firmly rooted in prosodic theory. Detecting conflicts is equally unnecessary, since each language dictates how conflicts are resolved through its constraint ranking. There is no need to describe conflicting representations before they arise.

Most significantly, the conflict between syntax and prosody identified by Zubizarreta emerges as a central property of grammar organization. Consequently its effects are widespread both within and across languages. Language internally, I will show how Italian quantifier focus and focus under right dislocation diverge from the familiar clause-final focus paradigm in ways that are unexpected outside a constraint conflict approach. Crosslinguistically, I will show how alternative rankings of the same constraints account for specific focus paradigms in English and French and also for the focus-induced prosodic patterns examined in Truckenbrodt $(1995,1999)$ for Chichewa, Chi Mwi:ni and Kimatuumbi. I will also speculate about how the same prosodic constraints may derive the lack of a single culminant sentential stress in Chichewa.

Independent OT-analyses similar in spirit but using different constraints and examining different sets of languages have been pursued in Truckenbrodt (1998), Gutierrez-Bravo (2000), Büring \& Gutierrez-Bravo (2002), Büring (2001, 2002, 2003), Keller \& Alexopoulou (2001), Szendröi (2001, 2002), and Dehé (to appear). A property distinguishing among OT analyses concerns the hypothesis that prosodic and syntactic constraints form constraint blocks, as proposed in Szendröi (2001). Here I will argue for the opposite position, using the analyses of Italian and French to show that prosodic and syntactic constraints can intermingle.

I start in $\$ 2$ with the main structural assumptions and constraints. The analysis of Italian follows in $\S 3$ while $\S 4$ examines its extension to English, French and Chichewa. Section §5 examines stress assignment in Bengali, German, Italian and English and highlights the problematic aspects of syntactic models of stress. A brief discussion of the issues raised by this proposal concludes this study in $\S 6$.

\section{Structural Assumptions and Universal Constraints}

The following four sections characterize the set of structures competing for grammatical status and define the constraints assessing them.

\subsection{Properties of Competing Structures}

Following Grimshaw (1993, 1997) and Chomsky (1992, 1995), competing syntactic structures are built from an enumeration of lexical and functional items projecting their own phrasal projections and merging together in the familiar specifier, complement, and adjunct relations.

Note that Italian and French past-participles will be assumed to always raise to a higher projection than VP, an operation which explains their occurrence to the left of VP-stranded floating quantifiers (Belletti 1990). The related analysis can be easily determined along Vikner's (2001) analysis of V-to-I movement but it is omitted here because orthogonal to the prosodysyntax interaction.

I also assume that clause-final focus, including clause-final focused subjects, always involves leftward scrambling of any material generated to its right (Kayne 1994:77, Ordoñez 1997, Pinto 1997, Zubizarreta 1998, Frascarelli 2000, Costa 1998, 2001). Yet, nothing essential in this work hinges on this view of syntax and the proposed conflict-base approach is also compatible with the rightward movement operations defended in Büring \& Hartmann (1997) and Ackema \& Neeleman (2002). 
With respect to prosody, I closely follow Truckenbrodt's $(1995,1999)$ analysis of the relation between prosodic structure and main stress that has emerged over the last twenty years of prosodic research. Following Selkirk (1984, 1986, 1995), Hammond (1984), Halle \& Vergnaud (1987) and Hayes (1995), prosodic structure is organized in a layered hierarchy of prosodic constituents represented as a bracketed grid. The head of each constituent is represented via a grid-mark ' $x$ ' while round brackets indicate a constituent's boundaries. Each head projects into the next higher layer but only some are selected as heads for the constituents in the higher layer.

For example, in (4) below each lexical item is parsed into a phonological word headed by the most prominent syllable. Phonological words are in turn parsed into phonological phrases (P-phrases) headed by the most prominent phonological word and P-phrases are parsed into an intonational phrase (I-phrase) headed by the most prominent P-phrase. The utterance phrase (U-phrase) encompasses the whole sentence and here coincides with the only available I-phrase. Since they are easily recoverable, I will henceforth omit phonological words and whenever possible utterance phrases as well. Note that whenever only one I-phrase is present, its head identifies main stress since it necessarily also becomes the head of the omitted U-phrase.

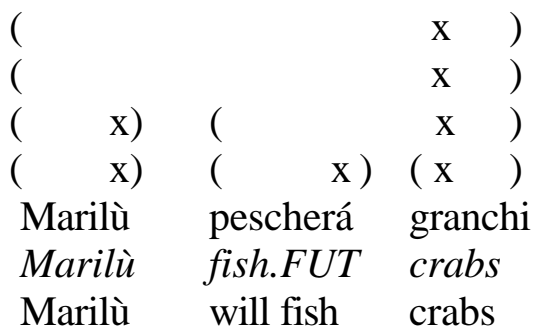

$\leftarrow$ utterance phrase $(\mathrm{U})$

$\leftarrow$ intonational phrases (I)

$\leftarrow$ phonological phrases $(\mathrm{P})$

$\leftarrow$ phonological words

The prosodic representation satisfies the two conditions below. The first establishes a one-toone relation between prosodic constituents and their heads (Hayes 1995). The second organizes prosodic constituents into hierarchical layers, with each layer exhaustively parsed into the next higher one in accord with Selkirk's Strict Layer Hypothesis (1984, 1986, 1995).

(5) Conditions on prosodic structures:

Headedness: each prosodic constituent has one and only one head.

Strict Layering: each prosodic constituent of layer $j$ is dominated by another constituent of layer $j$ or $j+1$ in accord with the prosodic hierarchy.

These conditions exclude structures like (6) and (7) below. Structure (6) fails to parse the second P-phrase into an I-phrase while (7) fails to head its second P-phrase. Compare them with the legitimate structures in (8) and (9), with main stress falling clause finally in (8) and clause initially in (9), depending on which P-phrase is selected as head for the I-phrase.

(6) Illegitimate:

$$
\begin{array}{lll}
(\mathrm{x}) & & \mathrm{I} \\
(\mathrm{x}) & (\mathrm{x}) & \mathrm{P}
\end{array}
$$

\begin{tabular}{|c|c|c|}
\hline \multirow[t]{3}{*}{ (6) } & Illegitimate: & Mary likes John \\
\hline & & $(x$ \\
\hline & & 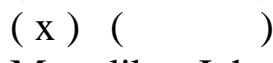 \\
\hline (7) & Illegitimate: & Mary likes John \\
\hline
\end{tabular}


The conditions in (5) above allow for recursive prosodic layers. Prosodic recursion is defended in Ladd (1986) and Selkirk (1995:443) and is necessary for Truckenbrodt's analysis of Kimatuumbi, which is part of the overall typology predicted here. Nevertheless for reasons of space I will omit prosodic recursion from most of this study. Its ungrammatical status in the relevant languages follows when the constraint NonRec against prosodic recursion (Truckenbrodt 1995, 1999; Deevy 1995) is sufficiently high in the constraint hierarchy, as discussed in $\S 4.3$.

I will also restrict the analysis to clauses with prosodically light arguments to enable their inclusion into the same P-phrase of the selecting verb (Nespor \& Vogel 1986). This is necessary to abstract away from the finer grained weight and rhythm constraints governing the prosodic parsing of complex sentences proposed by Mirco Ghini (1993). ${ }^{2}$ I will also parse simple root IP-clauses in a single intonational phrase (Nespor \& Vogel 1986:189) but Italian right dislocated constituents in separate intonational phrases as shown necessary by Frascarelli (2000:35).

Going back to the prosodic representation in (4) above, note how the layered heads determine a rhythmic grid which identifies main and secondary stress, with main stress falling on 'granchi' (crabs) and secondary stress on 'Marilù'. Main and secondary stress share an identical nature, both emerging from the grid's prominence peaks. Their position -always represented prior to the effect of rhythmic rules on secondary stress- is determined by the location of the heads in each prosodic constituent. It is this fundamental similarity of main and secondary stress and their dependency on prosodic constituency that is missed under the purely syntactic analyses of stress proposed in Zubizarreta (1998) or Cinque (1993:260).

Any linguistic structure obtained by combining together legitimate syntactic and prosodic structures may compete for grammatical status. Prosodic and syntactic structures vary independently of one another. Two competitors may share the same syntactic structure but differ in prosodic structure. Alternatively, they may share a similar prosodic structure but differ in

2 The inclusion of these constraints does not significantly affect the analysis but makes its exposition less transparent. There is also some minor disagreement between Ghini (1993:60) and Frascarelli (2000:32) on whether prosodic restructuring of objects can occur under sentence-wide focus. Here I follow Ghini (1993:47-48), who maintains that simple nouns introduced by determiners and prepositions remain sufficiently light to restructure into the precedent P-phrase. Two of Ghini's examples follow below.

(i) (Daró un libro $)_{\mathrm{P}}(\mathrm{a} \text { Gianni })_{\mathrm{P}}$

(Ex. 63, Ghini 1993, page 74) give.FUT.1 sg a book to John I will give a book to John

(ii) $(\text { Esaminerano il caso })_{\mathrm{P}}(\text { gli esperti })_{\mathrm{P}}$ (Ex. 62, Ghini 1993, page 73) examine.FUT.3pl the case the experts The experts will examine the case 
syntactic structure. Which combination is grammatical is determined by the constraints introduced below. ${ }^{3}$

\subsection{The Stress-Focus Constraint}

The data examined in this study always concern simple question answer pairs where focus affects a single constituent in the answer, namely the one corresponding to the wh-phrase (Halliday 1967:207, Rochemont \& Culicover 1990:18). For example, question (10) below focuses the entire VP of the corresponding answer, while question (11) only focuses the subject 'John'. The focused constituent is always marked by the subscript ' $\mathrm{f}$ ' and corresponds to the constituent marked as 'FOC' in the focus representation of Selkirk (1984).

Q: What has John done?

A: John has $[\text { written a letter }]_{f}$.

Q: Who has written a letter?

A: $\quad[\mathrm{John}]_{\mathrm{f}}$ has written a letter.

Jackendoff's (1972) observation that focus phrases are more prominent than non-focused ones is formalized in the Stress-Focus constraint below (henceforth 'SF'). SF demands that a focused phrase $\mathrm{XP}_{\mathrm{f}}$ be prosodically prominent in its focus domain, i.e. associated to a higher grid-mark column than any non-focused phrase YP within the same domain, where the focus domain in the data considered here always coincides with the entire sentence.

(12) Stress-Focus (SF): For any $\mathrm{XP}_{\mathrm{f}}$ and $\mathrm{YP}$ in the focus domain of $\mathrm{XP}_{\mathrm{f}}$, $\mathrm{XP}_{\mathrm{f}}$ is prosodically more prominent than $\mathrm{YP}$.

The SF constraint is adapted from Truckenbrodt's Focus constraint (1995:11) and is analogous to Zubizarreta's Focus Prominence Rule (1998:21). It is also similar to Schwarzschild's requirement that focus must be accented (1999:170) and it is entailed by Selkirk's Pitch Accent Prominence Rule (1995:563), which maintains that syllables carrying pitch accents -i.e. F-features eventually determining focus- are more prominent than non-accented ones. $^{4}$

SF penalizes those competitors that fail to stress focus. For example, SF is satisfied by A3 and A2 in (13) below but violated by A1 where main stress falls outside the focused VP.

3 The complexity of the representation does not undermine a precise assessment of what structure is grammatical in each language. Syntactic structures are determined by the standard diagnostics. Prosodic boundaries follow from phonological phenomena sensitive to them. These include clashinduced stress retraction (a.k.a. 'iambic reversal'), blocked at P-boundaries in Italian and English, Italian gemination (a.k.a. 'raddoppiamento sintattico') blocked by P-boundaries, Italian consonantal lenition and spiranthization, blocked by I- boundaries (Nespor \& Vogel 1986, Ghini 1993, Frascarelli 2000), and English prevocalic flapping of /t/ and /d/, blocked by U-boundaries (Nespor \& Vogel 1986, Hayes 1989:215). For further discussion see Nespor \& Vogel (1986), Ghini (1993), and Frascarelli (2000) for Italian, Fery (2000) for French, Truckenbrodt (1995) and Downing $(2002,2003)$ and therein references for Bantu languages, Hayes \& Lahiri (1991) for Bengali, and Ladd (1986), Nespor \& Vogel (1986), and Hayes (1989, 1995) for English.

${ }^{4}$ For an optimality analysis of focus marking see Schwarzschild (1999) where the constituent being focused emerges from competing F-feature distributions. The distribution that minimizes Ffeatures while preventing F-marking of discourse given information is selected as optimal. 
(13) Q: What has John done?

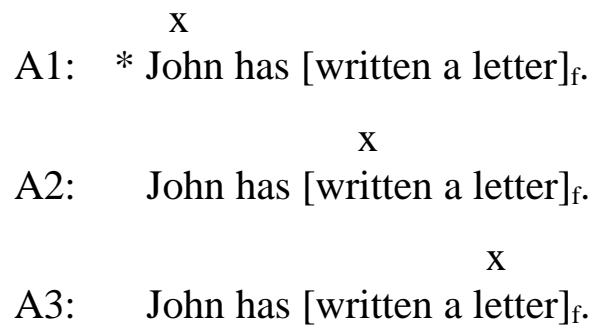

SF cannot govern where stress falls within a focused phrase. The choice between A2 and A3 above must follow from the constraints governing prosodic well-formedness. When sufficiently high ranked SF unleashes the conflict between prosodic and syntactic constraints because it requires the focused constituent to carry the highest prominence even when its best syntactic position does not coincide with the best location for main stress.

\subsection{Syntactic Constraints}

Ideally, any known syntactic requirement affecting movement, X-bar structure, Case and Theta-assignment should be part of the examined syntactic constraints. For reasons of space, most of this analysis is restricted to the constraints Stay and EPP proposed in Grimshaw (1993, 1997) and defined below. These fairly uncontroversial constraints are sufficient for most of our purposes and have been used under various names in a large number of OT-analyses, including Grimshaw \& Samek-Lodovici (1995, 1998), Samek-Lodovici (1996a, 2001), Bakovic (1998), Ackema \& Neeleman (1998), Costa (1998, 2001), Müller (2001), and Vikner (2001).

(14) Stay. No traces.

EPP. Clauses have subjects.

The Stay constraint is rooted in Chomsky's economy of movement $(1991,1992,1995)$ and is violated once by each trace (or copy under copy theory). Recent work by Grimshaw (2001) derives economy of movement from universal constraints on syntactic structures. These may eventually replace Stay, raising the prospect of finer grained prosody-syntax interactions than those examined in this work.

The EPP constraint renames Grimshaw's 'Subject' constraint and corresponds to Chomsky's Extended Projection Principle (1982). Following Grimshaw (1997:390), I assume it to follow from the requirement that the highest A-specifier —or the specifier of I-related heads such as $\mathrm{T}^{\mathbf{o}}$, $\mathrm{Agr}^{\circ}$, Nego - be overtly filled, which, as Grimshaw notes leaves the choice open to the theoretical development of the notions of 'A-specifier' and 'I-related head'. Following Grimshaw \& Samek-Lodovici (1995, 1998), I also assume that null expletives do not exist and that postverbal subjects simply leave the preverbal subject position unfilled, violating EPP (SamekLodovici 1996a, Alexiadou \& Anagnostopoulou 1999).

\subsection{Prosodic Constraints}

The prosodic constraints govern the mapping of syntactic structures into prosodic constituents and the position of prosodic heads. Collectively, the constraints considered here favor rightmost stress.

The first two constraints, Wrap and StressXP, govern the parsing of syntactic structures into P-phrases as defined in (15) and (16) below. They are imported from Truckenbrodt $(1995: 13,85)$ 
where they are used to explain the prosodic effects of focus in Chi Mwi:ni, Chichewa, and Kimatuumbi (see also Truckenbrodt 1997, 1999, Selkirk 1984, 1986, 1995).

(15) Wrap. Each lexically headed XP is contained inside a phonological phrase P.

(16) StressXP: Each lexically headed XP must contain a phrasal stress (where 'phrasal stress' refers to the head of a phonological phrase $\mathrm{P}$ ).

The Wrap constraint requires that all lexical items in a lexical projection be contained within a single P-phrase. Like Truckenbrodt, I assume Wrap to be categorical, i.e. violated at most once independently of how many P-phrases boundaries cut into a projection. This assumption is necessary for the prosodic analysis of Chichewa ditransitives discussed in $\S 4.3$.

The constraint StressXP requires that one of the lexical items in a lexical projection XP be promoted to head of a P-phrase. The head of the P-phrase counts as 'phrasal stress,' explaining the name of the constraint, and should not be confused with main stress, which only occurs at the utterance level.

When a phrasal XP-node consists of multiple XP-segments, as is the case with adjuncts, Wrap and StressXP need only hold of the lowest segment. ${ }^{5}$ As Truckenbrodt showed, under this definition Wrap and StressXP distinguish head-adjunct pairs from head-argument ones, making prosodic structures and eventually main stress sensitive to complement selection.

In presence of adjuncts Wrap and StressXP favor parsing each item on a P-phrase of their own, see (17) below.
$\left.\begin{array}{cl}\mathrm{x} & (\mathrm{x}) \mathrm{P} \\ \text { Adjunct } & {[\mathrm{vp} \mathrm{V}}\end{array}\right]$
$\leftarrow$ Wrap and StressXP both satisfied
a. [vp Adjunct $\left.\left[{ }_{\mathrm{vp}} \mathrm{V}\right]\right]$

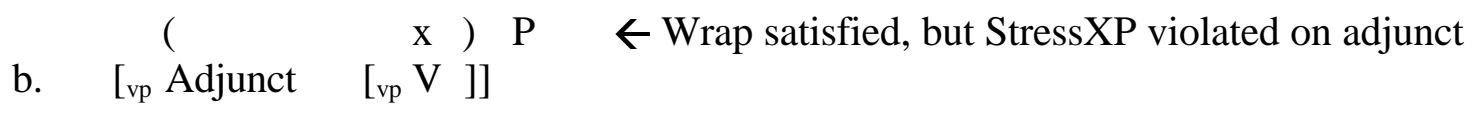

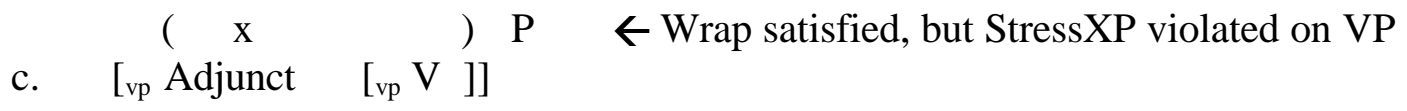

When a single argument is present, as in (18) below, Wrap and StressXP favor parsing argument and predicate into a single P-phrase headed on the argument. Phrasal stress falls on the argument because this simultaneously satisfies StressXP relative to both the argument and the VP. Phrasal stress on V would fail StressXP relative to the argument DP and phrasal stress on both items requires two P-phrases, failing Wrap. The order of the items is irrelevant.

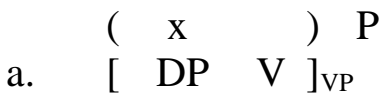
$\leftarrow$ Wrap and StressXP both satisfied

5 Truckenbrodt notes that this property follows from the definition of syntactic 'domination' in May (1985) and its role in the definition of StressXP and Wrap. According to May, a category A dominates B if and only if every segment of A dominates B. It follows that any item not dominated by the lowest phrasal segment of a projection XP is not dominated by XP. 

b. $\quad\left[\begin{array}{lll} & & \mathrm{x}\end{array}\right) \mathrm{P}$
$\leftarrow$ Wrap satisfied, StressXP violated
c. $\quad\left[\begin{array}{lll}(\mathrm{x}) & \mathrm{x} & \mathrm{x} \\ \mathrm{DP} & \mathrm{V}\end{array}\right]_{\mathrm{VP}} \mathrm{P}$
$\leftarrow$ Wrap violated, StressXP satisfied

Wrap and StressXP apply only to lexical projections in accord with Truckenbrodt's 'Lexical Category Condition' (1999:226) and Selkirk's 'Principle of Categorial Invisibility of Function Words' (1984:337) both asserting the invisibility of function words with respect to prosodic constraints. Lexical items raising into inflectional heads, however, will be assumed to remain lexical as far as Wrap and StressXP are concerned. This assumption is necessary to properly analyze Italian past-participles where verbs head-adjoined onto higher past-participle morphemes are still parsed within the same P-phrase of the following object. The consequences for the prosodic parsing of finite verbs raised into $\mathrm{I}^{\mathrm{o}}$ is examined in section $\$ 5.2$.

The last set of constraints, also from Truckenbrodt (1995), governs the position of heads in prosodic constituents, requiring them to occur rightmost (see also Prince 1983, Nespor \& Vogel 1986, McCarthy \& Prince 1993). Rightmost prominence is also required across utterance phrases via the constraint Head-U (Nespor \& Vogel 1986:223). The definitions follow the familiar format of alignment constraints in McCarthy \& Prince (1993) here extended to prosodic categories above the phonological word (Wiltshire 1998).

$$
\begin{array}{ll}
\text { Head-P (H-P). } & \begin{array}{l}
\text { Align(P-phrase, R, Head(P-phrase), R) } \\
\text { Align the right boundary of every phonological phrase with its head. }
\end{array} \\
\text { Head-I (H-I). } & \begin{array}{l}
\text { Align(I-phrase, R, Head(I-phrase), R) } \\
\text { Align the right boundary of every intonational phrase with its head. }
\end{array} \\
\text { Head-U (H-U). } & \begin{array}{l}
\text { Align(U, R, Head(U), R) } \\
\text { Align the right boundary of every utterance phrase U with its head. }
\end{array}
\end{array}
$$

These constraints are gradient, violated once for every position separating the head from the right edge of its prosodic phrase. ${ }^{6}$ For example, each of the three P-phrases in (20) below satisfies H-P, whereas H-I is violated twice because two potential head positions separate the head of the I-phrase from its right edge. Unused positions are marked as '_'.

$$
\begin{aligned}
& (\mathrm{x}-\overline{\mathrm{x}})(\overline{\mathrm{x}}) \mathrm{I} \\
& (\mathrm{x})(\mathrm{H} \\
& \text { Mary likes John }
\end{aligned}
$$

As Truckenbrodt points out, once combined with Wrap and StressXP the above constraints favor the alignment of a P-phrase's right boundary with the syntactic right boundary of lexical maximal projections, thus entailing the effects of Selkirk's (1995:456) alignment constraints without mentioning this specific relation in their definitions (for an OT-analysis of the prosodysyntax interaction in terms of Selkirk's constraints see Szendröi 2001).

${ }^{6}$ In Truckenbrodt's original definitions the constraints are sensitive to the prosodic structure intervening between head and edge across all prosodic layers. All of Truckenbrodt's results carry over under the simpler definitions proposed here. 
3Focus Induced Prosody-Syntax Interaction

From a descriptive point of view Italian appears to simultaneously allow for focus fronting, focus in situ, and rightward focus. Of these three paradigms the one most relevant for the syntaxprosody interface is rightward focus, which includes rightmost focus but also less well known cases of rightward but non-rightmost focus. Focus fronting and focus in situ emerge when rightward focus co-occurs with right dislocation; I return to them in $\$ 3.5 .1$.

The most well known instance of rightward focus is focus in clause-final position, which has been firmly established by a great number of studies, including Antinucci \& Cinque (1977), Calabrese (1982, 1992), Zubizarreta (1994, 1998), Belletti \& Shlonsky (1995), Samek-Lodovici (1996a), Pinto (1997), and Frascarelli (2000). Consider first the canonical case where an entire clause is focused, as in (21) below. Focus is here trivially clause-final since it coincides with the clause itself. Within the focused clause, the subject must occur preverbally, as shown in A1 below. Indeed the postverbal subject in A2 is acceptable only under a contrastive interpretation where 'John' is contrasted with a presupposed set of alternative potential winners. (Stress in capital, focus marked as ' $\mathrm{f}$ ').

Q: What happened?

A1: [ Gianni ha vinto la CORSA $]_{\mathrm{f}}$

John has won the race

John won the race

A2: $\quad *[\text { Ha vinto la corsa GIANNI }]_{\mathrm{f}}$ has won the race John

John won the race

7 As noticed by an anonymous reviewer, under specific circumstances subjects may occur postverbally even within a focused clause. For example, question $\mathrm{Q}$ in (i) below can be answered with a preverbal subject, as in A1 below, or a postverbal one, as in A2. The only difference is a slight hint that the subject has been or will be a discourse topic in A1 but not in A2. For example, A1 appears a more natural choice if discourse proceeds with a null subject referring to the police (see Samek-Lodovici 1996a). Subjects may also remain postverbal when specIP is occupied by an invisible locative (Pinto 1997).

(i) Q: What happened to Mary?

A1: [ La polizia l'ha ARRESTATA $]_{\mathrm{f}}$

The police her-has arrested

The police arrested her

A2: [ L'ha arrestata la POLIZIA $]_{\mathrm{f}}$

her-has arrested the police

The police arrested her

These cases show that constraints governing the expression of topics or the distribution of empty locatives might interact with the EPP constraint in determining the position of subjects in sentence-wide focus contexts. These cases however do not concern the syntax-prosody interface, which plays no relevant role in their analysis. They are also no exception to the paradigm under study, because focused clauses constitute trivial instances of clause-final focus, and can therefore be henceforth safely ignored. 
When only the subject is focused, however, it can always occur clause finally, see A1 in (22) below. Furthermore, if main stress remains rightmost the subject cannot occur preverbally, see A2.

(22) Q: Who won the race?
A1: L'ha vinta GIANNI $\mathrm{f}_{\mathrm{f}}$ it-has won John
JOHN won the race

\section{A2: *Gianni $\mathrm{f}_{\mathrm{f}}$ l'ha VINTA \\ John it-has won \\ John won it}

A similar distribution applies to any other focused constituent. Two examples respectively focusing an object and an indirect object rightmost in their clause are provided below.
Ho piantato in giardino un $\mathrm{MELO}_{\mathrm{f}}$
Context: What did you plant in the garden? have.1sg planted in garden an apple-tree
I planted an APPLE-TREE in the garden

Sono andato con Mario a ROMA $\quad$ Context: Where did you go with Mario?

am.1sg gone with Mario to Rome

I went to ROME with Mario

Rightmost focus structures occur in complementary distribution with cases of rightward but non-rightmost focus where a focused constituent occurs to the right of its canonical position but not rightmost in the clause.

A first such case occurs when focus co-occurs with right dislocation. The latter is a clause bound operation that optionally dislocates discourse-given constituents to the right periphery of the clause (Vallduví 1992, 1993, Zubizarreta 1994, Samek-Lodovici 1996b, Cecchetto 1999). Right dislocated phrases are easily recognized because they can be doubled by a clitic, may freely follow locative and temporal adjuncts, are always preceded by an intonational break, and can be preceded by an optional pause (here represented by a comma). Crucially, focus must always precede right dislocated constituents. For example, if a dislocated object is present, a rightward focused subject will still occur to the right of the verb but must precede the dislocated object; compare (25) and (26) below. Similar examples can be produced at will.

(25) Lo ha bevuto GIANNI, il vino

Context: Who has drunk the wine?

it has drunk John, the wine

JOHN drank it, the wine

(26) * Lo ha bevuto, il vino GIANNI fl $_{\mathrm{f}} \quad$ Context: Who has drunk the wine? it has drunk, the wine John

The second case of rightward but non-rightmost focus concerns focused quantifiers and was first observed by Frascarelli (2000:38) with respect to contrastive focus, but it carries over to new information focus. The nominal constituent containing focus occurs rightmost but the focused quantifier itself must precede the noun. An example is shown in A1 in (27) below, where the object containing the quantifier occurs to the right of the indirect object and hence clause 
finally, whereas focusing the quantifier itself in rightmost position produces the severely ungrammatical answers in A2 and A3. ${ }^{8}$

(27) Q: How many cherries have you given to Mary?

A1: Ho dato a Maria $\mathrm{TRE}_{\mathrm{f}}$ ciliege

have.1sg given to Mary three cherries

I have given THREE cherries to Mary

A2: * Ho dato ciliege a Maria $\mathrm{TRE}_{\mathrm{f}}$ have.1sg given cherries to Mary three

A3: * Ho dato a Maria ciliege $\mathrm{TRE}_{\mathrm{f}}$ have.1sg given to Mary cherries three

The bare noun following the quantifier in A1 above is not right dislocated. Right dislocated bare-nouns require doubling by the clitic $n e$ 'of-them' and must be preceded by the preposition $d i$ 'of', which is responsible for their case marking; see (28) below. The bare noun in A1 above lacks all these properties. Furthermore, unlike genuine right dislocated phrases it cannot follow locative and temporal adjuncts, see (29) and (30) below.

(28) Q: How many cherries have you given to Mary?

A: $\quad$ Ne ho date a Maria $\mathrm{TRE}_{\mathrm{f}}$, di ciliege of-them have.1sg given.Fpl to Mary three, of cherries

I have given THREE cherries to Mary

(29) Q: How many cherries have you given to Mary yesterday?

A: $\quad$ * Ho dato a Maria $\mathrm{TRE}_{\mathrm{f}}$, ieri, ciliege have.1 sg given to Mary three, yesterday, cherries I have given THREE cherries to Mary yesterday

(30) Q: How many cherries have you given to Mary in the garden?

A: $\quad$ * Ho dato a Maria $\mathrm{TRE}_{\mathrm{f}}$, in giardino, ciliege have.1 sg given to Mary three, in garden, cherries I have given THREE cherries to Mary in the garden

Examples with rightward but non-rightmost focused quantifiers can be produced at will by changing the verb or the numeral involved. Which argument is quantified is also irrelevant. Cases involving quantified subjects will be examined in $§ 3.3$.

The right dislocation and quantifier cases just surveyed show that Italian clause-final focus is just an instance of a more general paradigm involving rightward but not necessarily rightmost

${ }^{8}$ If pronouns are allowed, the most natural answer to question Q in (27) above shows pronominal clitics followed by clause-final focus as in (i) below.

(i) Gliene ho date $\mathrm{TRE}_{\mathrm{f}}$ to-her-of-them have.1sg given.Fpl three

I have given her three of them 
focus. Language-internal distributions of this kind are not easily captured by parametric accounts because parameters cannot switch value within the same grammar (Samek-Lodovici 1996a, McCarthy 2002:109). Once interpreted in terms of constraint conflict, however, the same distribution emerges naturally from the interaction of the proposed constraints. As the next few sections will show, rightmost focus occurs because main stress is pushed rightmost by the prosodic constraints and this in turn pulls focus rightmost to satisfy the stress-focus constraint SF at the cost of lower ranked syntactic constraints. Whenever higher-ranked constraints prevent stress from occurring rightmost, the prosodic constraints do not cease to push stress as far to the right as possible, producing rightward but non-rightmost focalization.

I start with sentence-wide focus, where no syntax-prosody interaction may occur, then move to rightmost focus, and finally consider rightward but non-rightmost focus. I only examine competitors that outperform the grammatical structure on at least one constraint since any other alternative is necessarily worse and therefore ungrammatical (Prince and Smolensky 1993, Samek-Lodovici and Prince 1999). Where convenient I omit constraints that are violated in equal measure by all competitors under discussion because they cannot affect the outcome of the competition.

\subsection{Sentence-wide Focus}

When focus is sentence-wide, stress necessarily matches focus, thereby satisfying SF. The prosodic constraints can then be satisfied independently of the syntactic ones, with prosodic constraints favoring rightmost stress and syntactic constraints favoring preverbal subjects and unmoved internal arguments; see the example below involving an intransitive verb.

$$
\begin{array}{lr}
\left(\begin{array}{l}
\mathrm{x} \\
(\mathrm{x}) \mathrm{I} \\
(\mathrm{x}) \mathrm{P}
\end{array}\right. \\
{[\text { Gianni ha riso }]_{\mathrm{f}}}
\end{array}
$$

John has laughed

John has laughed
Context: What happened?

Constraint interaction is best examined via comparative tableaux like T1 below, adapted from Prince (2000). The grammatical structure is given in row (a) with its constraint violations, while ungrammatical alternatives are listed in the bottom row(s) with their violations. To avoid cluttering the tableaux with too much information, I have left all traces unindexed. They are easily identified, given that the trace of the subject occurs leftmost in the VP, followed by the trace of the verb, followed by that of the object and indirect object (if they are present).

The constraints are ordered left to right by decreasing rank and marked in losers' rows as ' $\mathrm{W}$ ' when favoring the winner and ' $\mathrm{L}$ ' when favoring the loser. As Prince notes, W- and L-marked constraints are the only ones relevant to the competition because the observed grammatical structure wins if and only if at least one W-marked constraint dominates all the L-marked constraints favoring the loser.

In the case at hand, structure (a) with a preverbal subject beats the alternative in (b), stranding the subject clause finally. SF is satisfied by both structures and thus remains neutral. The prosodic constraints, including the omitted StressXP and Wrap, are also all satisfied by both competitors. The position of the subject is determined by the syntactic constraints alone, with EPP outranking Stay as proposed in Grimshaw \& Samek-Lodovici (1995, 1998). 


\begin{tabular}{|c|c|c|c|c|c|}
\hline 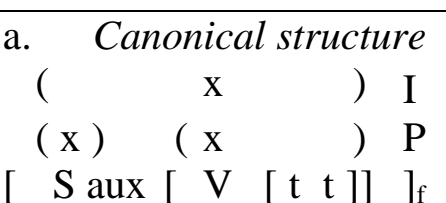 & & & & & $* *$ \\
\hline T1 - Sentence-wide focus & $\mathrm{SF}$ & $\mathrm{H}-\mathrm{P}$ & H-I & EPP & Stay \\
\hline 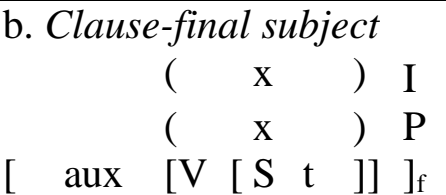 & & & & $W$ & $L$ \\
\hline
\end{tabular}

\subsection{Clause-final Focus}

When the subject is focused, the very same clause-final subject structure that is ungrammatical under sentence-wide focus becomes grammatical. ${ }^{9}$ The prosodic constraints place stress rightmost as in (a) in T2 below. SF in turn forces focus to match the position of stress, thus favoring a clause-final subject even if this violates lower ranked syntactic constraints. For example, the preverbal-subject alternative in (b) fares better on EPP but is ungrammatical because stress no longer matches focus, failing the higher ranked SF constraint. The EPP violation that is fatal to postverbal subjects under sentence-wide focus is thus imposed by the SF> EPP ranking when focus applies to the subject alone.

\begin{tabular}{|c|c|c|c|c|c|}
\hline 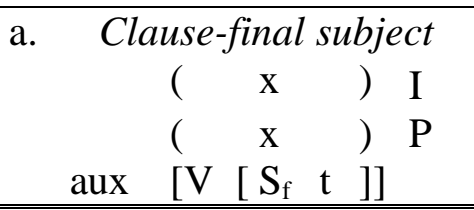 & & & & $*$ & $*$ \\
\hline T2 - Focused subject 1 & SF & H-P & H-I & EPP & Stay \\
\hline 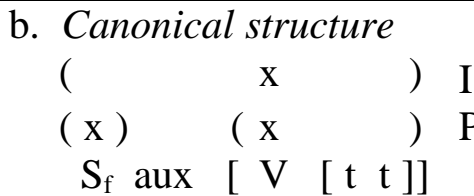 & $W$ & & & $L$ & $* *$ \\
\hline
\end{tabular}

SF and EPP can be satisfied both at once by placing stress on a preverbal subject as in (b) below, which is also the structure selected by English for this focus context. ${ }^{10}$ This structure however fails to right-align the head of the I-phrase and thus violates H-I. Its ungrammatical status shows that Italian ranks the prosodic constraint H-I above the syntactic constraint EPP, and, since EPP outranks Stay, above Stay as well.

${ }^{9}$ Postverbal focused subjects join the P-phrase of the preceding verb. Focused phrases always join the P-phrase of an immediately preceding verb independently of the syntactic category of the focused phrase; see Frascarelli (2000:28).

${ }^{10}$ This structure should not be confused with focus fronting, where the constituents following focus are right dislocated; for discussion see $\$ 3.5 .1$ as well as Vallduví (1992:104), SamekLodovici (1996b), and Frascarelli (2000). 


\begin{tabular}{|c|c|c|c|c|c|}
\hline 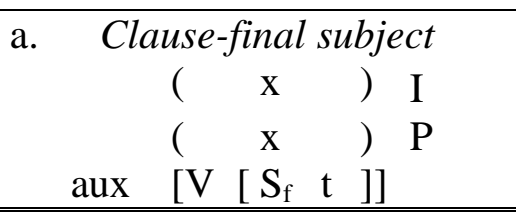 & & & & $*$ & $*$ \\
\hline T3 - Focused subject 2 & SF & $\mathrm{H}-\mathrm{P}$ & $\mathrm{H}-\mathrm{I}$ & EPP & Stay \\
\hline 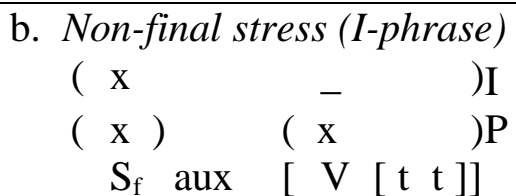 & & & $W$ & $L$ & $\begin{array}{l}* * \\
W\end{array}$ \\
\hline
\end{tabular}

A variant of the above competitor parses the entire sentence into a single P-phrase with a misaligned leftmost head that violates H-P, see (b) below. This structure also violates StressXP because it lacks phrasal stress on VP. Structure (a) emerges victorious once again because prosodic constraints -here either StressXP or H-P- outrank the syntactic constraints EPP and Stay (the latter again by transitivity given that EPP $>>$ Stay).

\begin{tabular}{|c|c|c|c|c|c|c|}
\hline 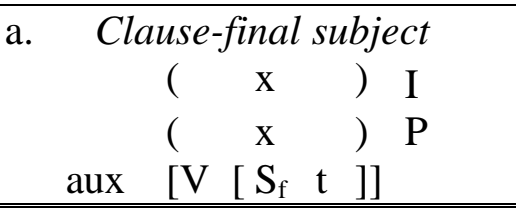 & & & & & $*$ & $*$ \\
\hline T4 - Focused subject 3 & SF & $\mathrm{H}-\mathrm{P}$ & StressXP & $\mathrm{H}-\mathrm{I}$ & EPP & Stay \\
\hline 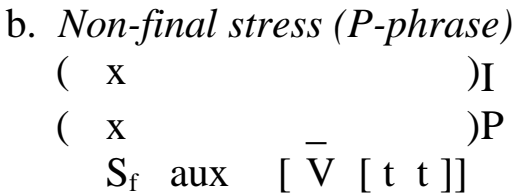 & & $*$ & $\begin{array}{l}* \\
W\end{array}$ & & $L$ & $\begin{array}{l}* * \\
W\end{array}$ \\
\hline
\end{tabular}

The above tableaux exhaust the competitors that might outperform the grammatical structure (a) by avoiding the associated EPP and Stay violations. Any other structure consistent with the assumptions in $\$ 2$ necessarily incurs the same violations of (a) and hence cannot outperform it. Italian rightmost focused subjects are thus forced rightwards by SF and the prosodic constraints favoring rightward stress at the cost of the lower ranked syntactic constraints.

The same analysis extends to rightmost focused arguments and verbs. Here, I only consider focused objects like the one in (23) above because they provide evidence for further ranking relations between syntactic and prosodic constraints. As in the above analysis for subjects, clausefinal focused objects like the one in (a) below outperform objects remaining in situ like the one in (b) where stress becomes non-final. Structure (a) costs one more Stay violation than (b) due to the leftward shifted indirect object but satisfies H-I. Its grammatical status confirms the higher rank of prosodic H-I relative to syntactic Stay already observed in T3 above.

\begin{tabular}{|c|c|c|c|c|c|}
\hline 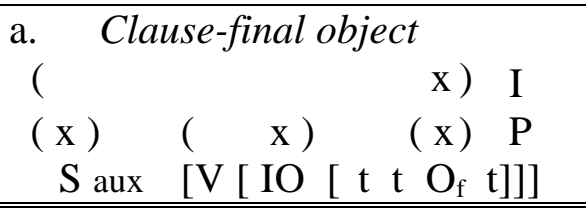 & & & & & $* * *$ \\
\hline T5 - Focused object 1 & SF & $\mathrm{H}-\mathrm{P}$ & H-I & EPP & STAY \\
\hline 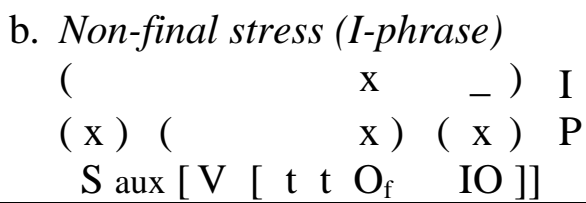 & & & $W$ & & $* *$ \\
\hline
\end{tabular}


The grammatical structure (a) fails to wrap the verb and its arguments into a single P-phrase. Further movement of the indirect object as in (b) below avoids this Wrap violation but costs an additional Stay violation. The grammatical status of (a) thus requires Stay to outrank Wrap, showing that prosodic and syntactic constraints can be intermingled, a property that will emerge again in the analysis of French and which I will return to in $\S 6$.

\begin{tabular}{|c|c|c|c|c|c|c|}
\hline 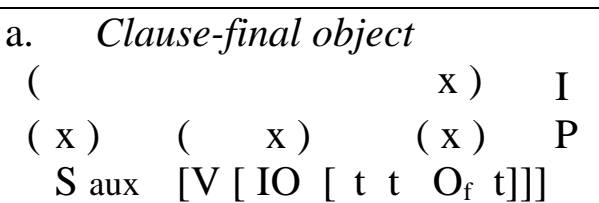 & & & & & $* * *$ & $*$ \\
\hline T6 - Focused object 2 & SF & H-P & H-I & EPP & Stay & Wrap \\
\hline 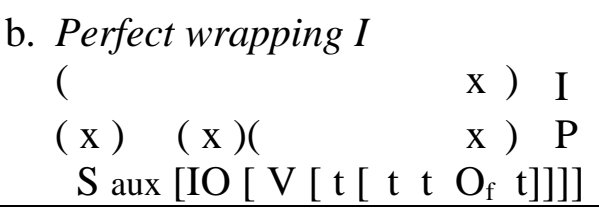 & & & & & $\begin{array}{c}* * * * \\
W\end{array}$ & $L$ \\
\hline
\end{tabular}

Perfect wrapping can also be attained by parsing the projection headed by the raised $\mathrm{V}$ into a single P-phrase, as in (b) in T7 below. This structure violates StressXP on the indirect argument and its ungrammatical status reveals the prosody-internal ranking StressXP $>>$ Wrap.

\begin{tabular}{|c|c|c|c|c|c|c|c|}
\hline 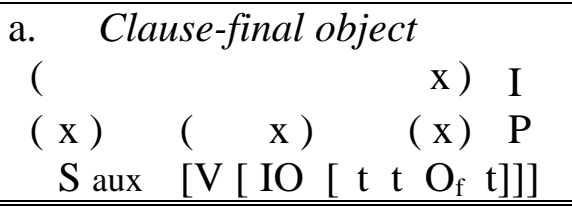 & & & & & & $* * *$ & * \\
\hline T7 - Focused object 3 & SF & $\mathrm{H}-\mathrm{P}$ & StressXP & $\mathrm{H}-\mathrm{I}$ & EPP & Stay & Wrap \\
\hline 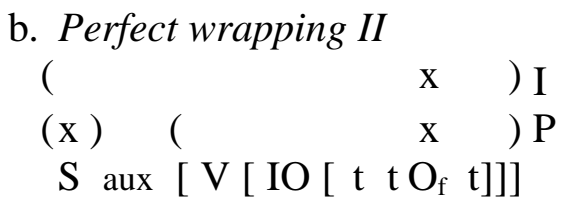 & & & $W$ & & & $* * *$ & $L$ \\
\hline
\end{tabular}

The ranking relations uncovered so far, which are responsible for Italian rightmost focus, are listed below. The prosodic constraints H-I together with either H-P or StressXP force stress rightmost. SF in turn forces focus to match this rightmost position even when this violates the lower ranked EPP and Stay.

$$
\begin{aligned}
& \{\mathrm{SF}, \mathrm{H}-\mathrm{I}\}>\text { EPP }>>\text { Stay }>>\text { Wrap; } \\
& \{\text { H-P OR StressXP }\}>\text { EPP; } \\
& \text { StressXP >> Wrap. }
\end{aligned}
$$

\subsection{Focused Quantifiers}

Focused quantifiers provide our first case of rightward but non-rightmost focus. An example involving quantified subjects follows in (33) below. The subject is headed by the quantifier as shown in (34). Like the object cases in $\$ 3$ above, only the quantifier is focused: sentence (33) is a legitimate answer to the quantifier focusing question Q1 in (35) below but not to subject focusing question Q2, whose answer requires stress on bambini 'children'. 
(33) Sono arrivati $\mathrm{TRE}_{\mathrm{f}}$ bambini

Context: How many children arrived?

are arrived three children

THREE children have arrived

(34) [ $\mathrm{TRE}_{\mathrm{f}}[\mathrm{NP}$ bambini ]]

three children

(35) Q1: How many children have arrived?

Q2: Who has arrived?

The entire subject occurs clause finally, displaced from its canonical preverbal position, but the focused quantifier itself cannot do so; compare (33) above with the severely ungrammatical (36) and (37) below.

(36) * Sono arrivati bambini $\mathrm{TRE}_{\mathrm{f}} \quad$ Context: How many children arrived? are arrived children three

(37) * Bambini sono arrivati $\mathrm{TRE}_{\mathrm{f}} \quad$ Context: How many children arrived? children are arrived three

Note that the noun following the quantifier in (33) is not right dislocated. It cannot follow dislocated temporal or locative adjuncts -see (38) and (39) below- and it is not doubled by the clitic $n e$ 'of-them' nor introduced by the preposition $d i$ 'of' as genuinely dislocated bare nouns do, as shown in (40).

(38) * Sono arrivati $\mathrm{TRE}_{\mathrm{f}}$, oggi, bambini

Context: How many children arrived yesterday? are arrived three, today, children

(39) * Sono arrivati $\mathrm{TRE}_{\mathrm{f}}$, qui, bambini

Context: How many children arrived here? are arrived three, here, children

(40) a. Context: How many children arrived here today?

b. Ne sono arrivati $\mathrm{TRE}_{\mathrm{f}}$, oggi, qui, di bambini of-them are arrived three, today, here, of children

Any adequate analysis of Italian clause-final focus must explain why quantifiers of this kind cannot focus clause finally while the constituent they project can, even though it is not itself focused. To answer this question we need to identify what blocks extraction of the nominal complement out of the quantifier projection, since this operation would enable the quantifier to focus clause finally. Frascarelli (2000) proposes that the complement constitutes a non-maximal projection and therefore cannot move. I prefer to capitalize on the observation that the quantifier blocks trace government by the preceding verb. Extraction of a bare NP from a governed position is actually possible, see the declarative clause and its object extraction counterpart in (41) below, but it is blocked when the NP is quantified, see (42). 
(41) a. Ho visto bambini molto ricchi

have.1sg seen children very rich

I have seen very rich children

b. Cosa hai visto?

what have.2sg seen?

What did you see?

(42) a. Ho visto tre bambini molto ricchi

have. 2 sg seen three children very rich

I have seen three very rich children

b. $\quad *$ Cosa hai visto tre?

what have.2sg seen three?

What did you see three?

Focusing the quantifier in rightmost position is thus prevented by the T-Gov constraint from Grimshaw (1997) which requires traces (or copies under copy-theory) to be governed by an appropriate governor (Rizzi 1990); its definition follows below.

T-Gov. A trace is governed.

Focused quantifiers cannot occur rightmost because extracting their complement violates T-Gov. For example, the non-final focused quantifier of (33) above repeated in (a) below violates $\mathrm{H}-\mathrm{P}$, StressXP, and EPP but nevertheless beats the alternative with rightmost focus in (b) because it satisfies the higher ranked T-Gov.

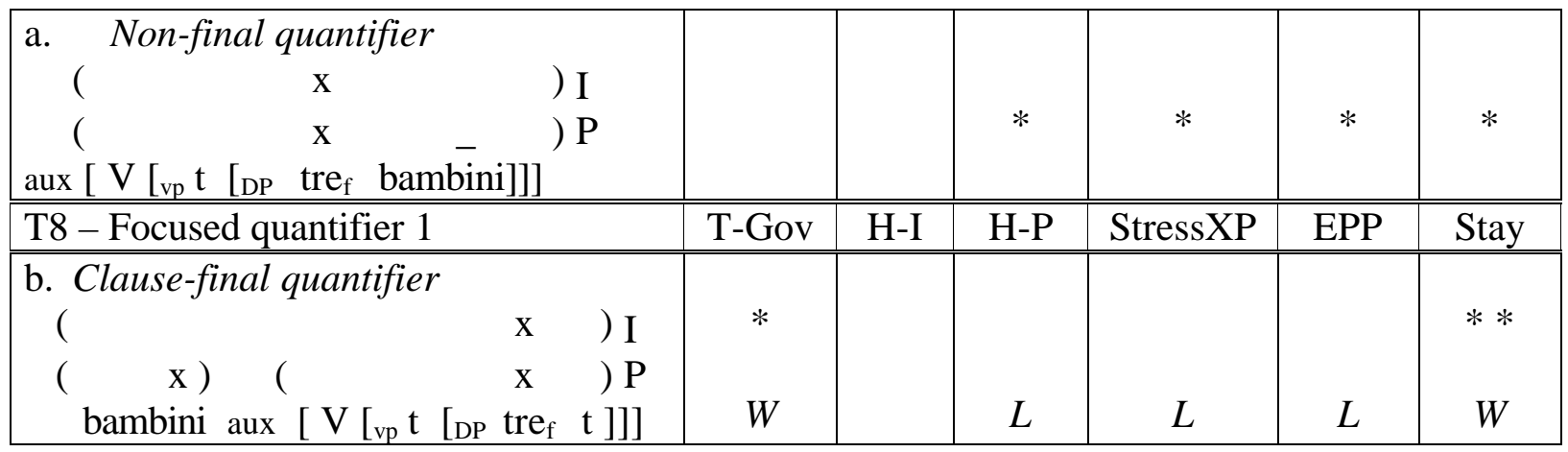

SF requires focus to match stress but this time H-I cannot pull stress rightmost because T-Gov prevents focus from occurring there. Stress is instead pulled as far to the right as is consistent with T-Gov and SF by placing the entire subject rightmost. As (a) in T9 below shows, this structure fails EPP, StressXP, and H-P but provides a better aligned I-head thus satisfying H-I. The preverbal subject alternative in (b) satisfies all above constraints but fatally violates the higher-ranked H-I. 


\begin{tabular}{|c|c|c|c|c|c|c|}
\hline 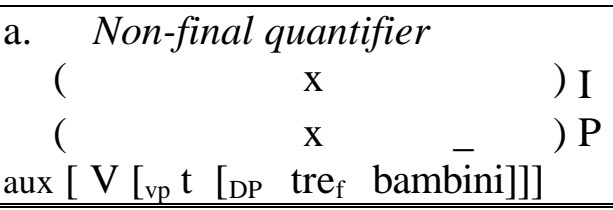 & & & $*$ & $*$ & $*$ & $*$ \\
\hline T9 - Focused quantifier 2 & T-Gov & $\mathrm{H}-\mathrm{I}$ & H-P & StressXP & EPP & Stay \\
\hline 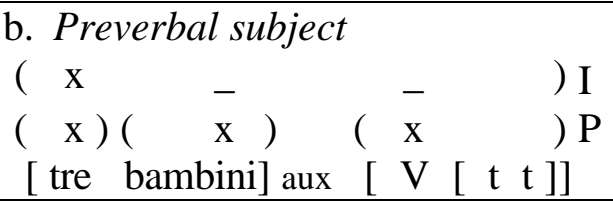 & & $W$ & $L$ & $L$ & $L$ & $\begin{array}{l}* * \\
W\end{array}$ \\
\hline
\end{tabular}

Conflict-based constraint interaction thus captures the fundamental similarity between rightmost and rightward but non-rightmost focus. In both cases stress is pulled rightward by the prosodic constraints and focus matches stress due to SF. Their complementary distribution follows from the need to simultaneously satisfy SF and T-Gov, which determines how far right stress and focus can be placed.

In comparison with structural approaches, the above analysis need not posit any ad-hoc devices or rules to explain why the constituent containing focus may occur in rightmost position even though it is not itself focused. Quantifier focus also challenges any approach relying on a syntactic account of stress because it constitutes an exception to the rightmost-stress generalization. For example the stress system proposed in Zubizarreta (1998), which assigns prosodic prominence to rightward syntactic branches, would incorrectly assign stress to the quantifier complement. This problem cannot be corrected by assuming that the complement is invisible to stress, as Zubizarreta assumes for English unfocused phrases, because prosodic visibility is a necessary prerequisite for her analysis of clause-final focus cases.

Finally, note that the above analysis further supports the case for constraint intermingling since it requires T-Gov to outrank the prosodic constraints H-P and StressXP, which in turn were previously found to dominate EPP and Stay.

\subsection{Focus under Right Dislocation}

Right dislocation constructions provide the second case where main stress and focus occur rightward but not rightmost. Right dislocated phrases never occur outside their own clause ${ }^{11}$ (Cecchetto 1999), yet focus precedes all dislocated phrases and carries main stress. For example, a postverbal focused subject followed by a right dislocated indirect object has the prosodic structure shown below, with stress occurring non-finally on the subject and the dislocated object within an I-phrase of its own (right dislocated phrases always require their own I-phrase; see Frascarelli 2000).

11 The examples below from Cecchetto (1999) show that the object of a sentential subject cannot be dislocated to the right of the matrix clause. The dislocated object is underlined.

(i) [Averlo finito, l'articolo] mi ha fatto bene to-have-it completed, the article, to-me has made good

As for the article, completing it helped me

(ii) $*$ [Averlo finito $] \mathrm{mi}$ ha fatto bene, l' articolo 
$\left(\begin{array}{l}\mathrm{x} \\ (\quad \mathrm{x}\end{array}\right)\left(\begin{array}{l}- \\ \mathrm{x}\end{array}\right) \mathrm{U}$

(44) Le ha parlato Gianni $\mathrm{f}_{\mathrm{f}}$ a Maria to-her has.3sg spoken John, to Mary

JOHN spoke to her, to Mary
Context: Who spoke to Mary?

I follow the analysis attributed to Kayne in Cecchetto (1999) and anticipated in Kayne (1994) where right dislocated constituents raise leftwards to the specifier of a topic projection followed by raising of the entire IP-remnant to the specifier of a second immediately higher projection. ${ }^{12}$ The corresponding structure for (44) above is given below. Note that the focused subject occurs postverbally within the raised IP but it is no longer final within the clause root node 'Topic2'.

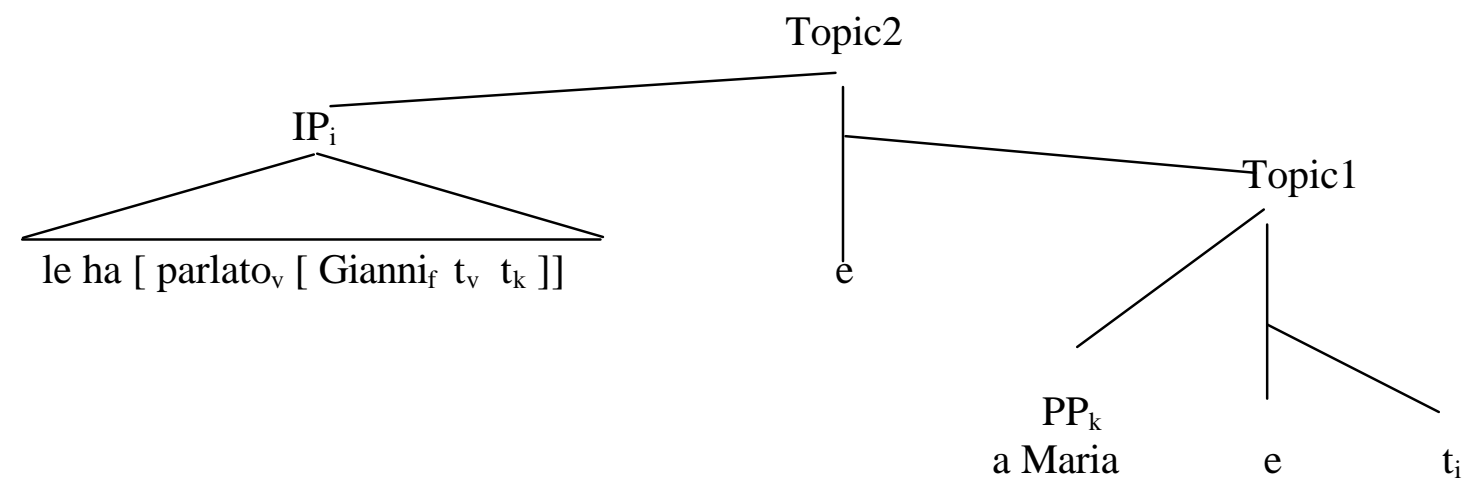

Once again any adequate analysis of Italian rightward focus must explain on one hand why right dislocation prevents focus from occurring rightmost in its clause and on the other why focused constituents are still forced to occur rightward even though they cannot occur rightmost.

With respect to the first question, I simply assume that discourse-given constituents tagged for right dislocation must raise to Kayne's topic projection and follow any non-tagged constituents. This requirement is formalized through the RD constraint below which is violated once for every constituent that follows a right dislocated constituent ${ }^{13}$. Note that RD does not affect any of the

12 Other analyses are possible, including one discussed by Cecchetto (1999) as well as alternatives based on rightward adjunction. Selecting one or the other does not affect the argument developed in this section.

13 Multiple dislocations necessarily violate $\mathrm{RD}$ but that does not prevent it from forcing dislocation. Consider the competition between (i) and (ii) below under the assumption that the object and indirect object are tagged for dislocation and that the indirect object dislocates in (i) but not in (ii). Condition (b) of RD is necessarily violated once in both structures because one of the dislocated items will necessarily follow the other, but condition (a) of RD is violated only by (ii), making it suboptimal whenever RD is sufficiently high-ranked.

(i) Gliel'ho DATA, [a Marco], [la bottiglia di champagne] him-it have.1sg given, to Mark, the bottle of champagne I have given it to him, the bottle of champagne, to Mark

(ii) * L'ho data [a MARCO], [la bottiglia di champagne] him have.1sg given to Mark, the bottle of champagne I have given it to Mark, the bottle of champagne 
OT-analyses proposed so far because none of the considered structures contained phrases tagged for right dislocation.

(46) RD: Discourse given constituents tagged for right dislocation occur (a) in the specifier of a topic projection, and (b) rightmost within their clause.

When RD is ranked sufficiently high, as in Italian, it forces focus to precede any right dislocated constituents, even if this worsen the right-alignment of the prosodic heads eventually responsible for main stress. This point is illustrated in tableaux T10 below. The right dislocation structure (44) repeated in (a) fails to place stress rightmost in the utterance violating $\mathrm{H}-\mathrm{U}$. Alternative (b) with rightmost focus and rightmost stress satisfies H-U and incurs fewer Stay violations, but the right dislocated constituents fail to occur rightmost, violating the higherranked RD constraint. ${ }^{14}$

Obviously H-U cannot be satisfied by assigning main stress rightmost on the dislocated phrase as in (c) either, because this violates the higher ranked SF constraint.

\begin{tabular}{|c|c|c|c|c|c|c|c|}
\hline 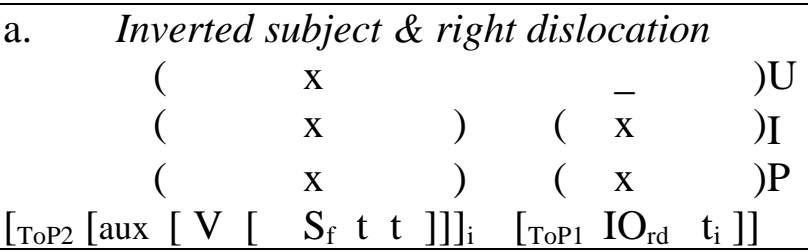 & & & $*$ & & & $* * *$ & \\
\hline T10 - Right dislocation 1 & $\mathrm{SF}$ & $\mathrm{RD}$ & $\mathrm{H}-\mathrm{U}$ & $\mathrm{H}-\mathrm{I}$ & $\mathrm{H}-\mathrm{P}$ & Stay & Wrap \\
\hline 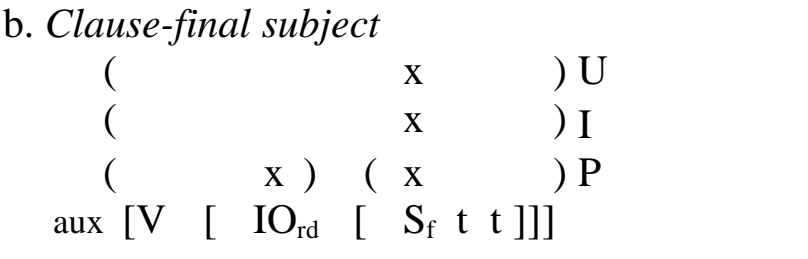 & & $*$ & $L$ & & & $* *$ & $*$ \\
\hline 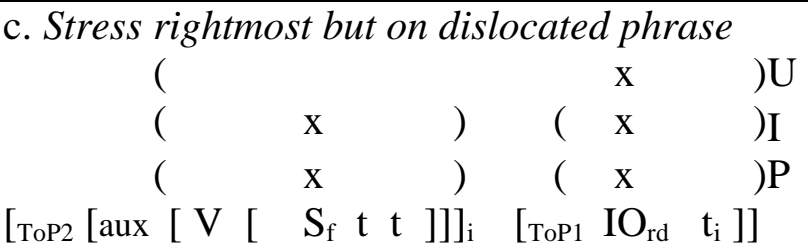 & $W$ & & $L$ & & & $* * *$ & \\
\hline
\end{tabular}

We may now examine why focus occurs rightward even though it cannot occur rightmost. Failure to right-align the head of the U-phrase due to right dislocation does not stop H-I from favoring right-aligned heads on I-phrases, which pulls stress rightmost in the first I-phrase. Focus in turn matches the position of stress due to SF and therefore occurs rightward.

There is no fixed order among right dislocated constituents (Vallduví 1992): for example, reversing the order of the dislocated items in (i) above does not affect its grammaticality. This implies that $\mathrm{RD}$ is insensitive to the internal structure of dislocated constituents, otherwise heavier constituents would precede lighter ones. This property is captured by defining condition (b) of RD as violated once for each $R D$-relevant phrasal node c-commanded by the dislocated item (i.e. following it), where 'RD-relevant' phrasal nodes are never dominated by any other phrasal node c-commanded by the dislocated item.

14 The empty head of Topic1 in structure (45) above is assumed to govern the trace of its complement so that T-Gov is satisfied across all competing structures. Even if T-gov were violated structure in (a) would remain grammatical under the ranking $\mathrm{RD}>>\mathrm{T}-\mathrm{Gov}$. 
This is shown below where the postverbal focused subject in (a) shows a better aligned I-head on the first I-phrase than the structure with a preverbal subject in (b). Since H-I outranks EPP structure (a) is preferred to (b).

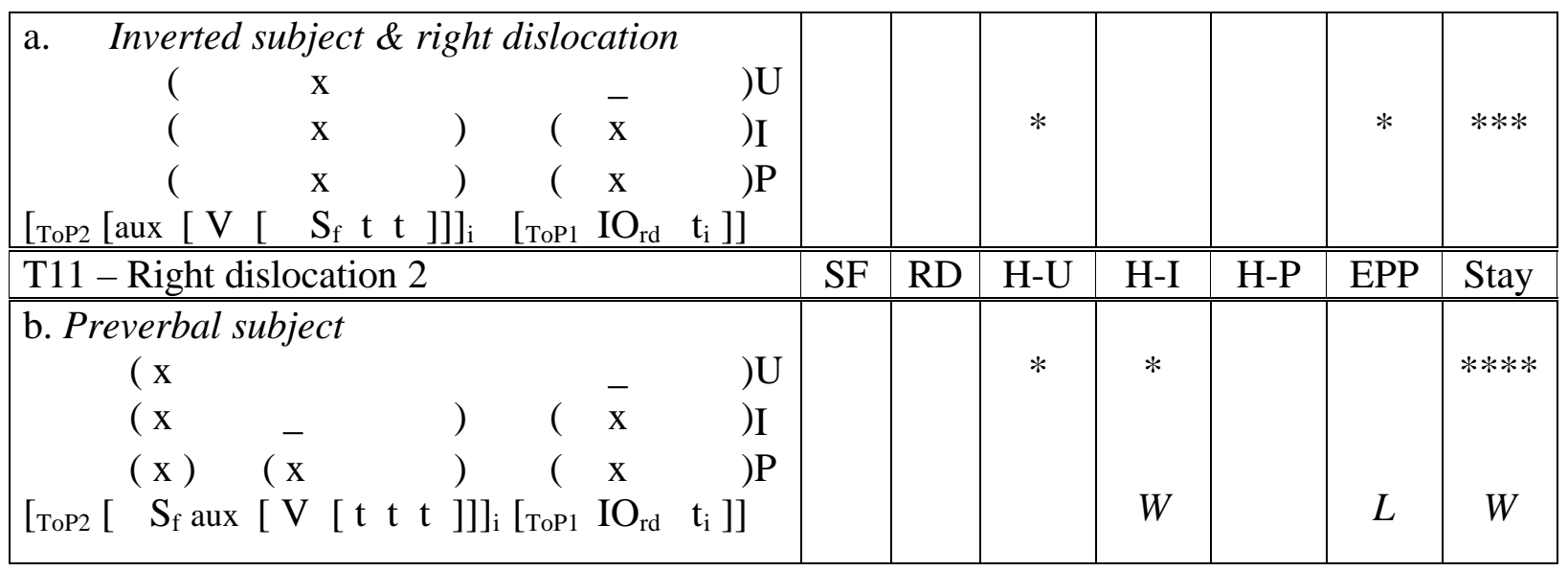

Like quantifier focus, right dislocation cases are problematic for approaches based on syntactic analyses of stress. Selecting the right daughter of any branching node as the prosodically most prominent incorrectly assigns main stress to right dislocated items. One might therefore be tempted to stipulate that right dislocated phrases are invisible to main stress assignment, as Zubizarreta (1998) does for English unfocused phrases. This choice fails to explain, however, why the distribution of prominence peaks in right dislocated constituents perfectly mirrors that of their non-dislocated counterparts, as further discussed in $§ 5.1$. The same distribution is unproblematic in the analysis proposed here where prominence is governed by the prosodic constraints, whatever the status of a constituent. Right dislocated constituents are then expected to show the same internal intonational contour of non-dislocated phrases and indeed they do. For example, the intonational contour for the right dislocated clause in (47) below, discernible as secondary and tertiary prominence peaks, perfectly mirrors the one associated to simple subjectverb declarative clauses.

(47) a. Context: Who knew that Mary had left?

$\begin{array}{llll}( & & & - \\ ( & \mathrm{x} & ( & \mathrm{X} \\ ( & \mathrm{x} & (\mathrm{x}) & (\mathrm{x}) \mathrm{P}\end{array}$

b. Lo sapeva Gianni $\mathrm{f}_{\mathrm{f}}$, che Maria era partita

it knew.3sg John, that Mary was left

JOHN knew it, that Mary had left

\subsection{Conclusion}

The analysis presented so far provides a unified account of Italian rightward focus while confirming Zubizarreta's insight about the role of prosody. The observation that focus is pulled rightward to improve prosodic alignment even when it cannot occur rightmost constitutes the best evidence for Zubizarreta's result and against positing a fixed focus position at the clause edge. The same observation, however, challenges a syntactic approach to stress assignment like Zubizarreta (1998), which as it stands incorrectly assigns stress (and focus) rightmost even when this is disallowed. Such an approach does not appear to be easily revisable without reference to the very same prosodic constituents it was designed to avoid to let stress affect syntax prior to spell-out. 
Once all ranking relations are pulled together, including the relation $\mathrm{H}-\mathrm{P}>>$ Wrap established later in $\$ 5.2$, we obtain the chart below expressing the relations between prosody and syntax responsible for rightward focus in Italian. The syntactic re-arrangement of the clause follows from the low rank of EPP and Stay relative to most prosodic constraints and SF. The higher rank enjoyed by Right Dislocation and T-gov relative to H-P and StressXP blocks stress and focus from occurring rightmost in the relevant contexts, but the prosodic nature of stress, here preserved, ensures that even in these cases stress is pulled as far right as possible, and focus with it due to SF.

(48) Italian:

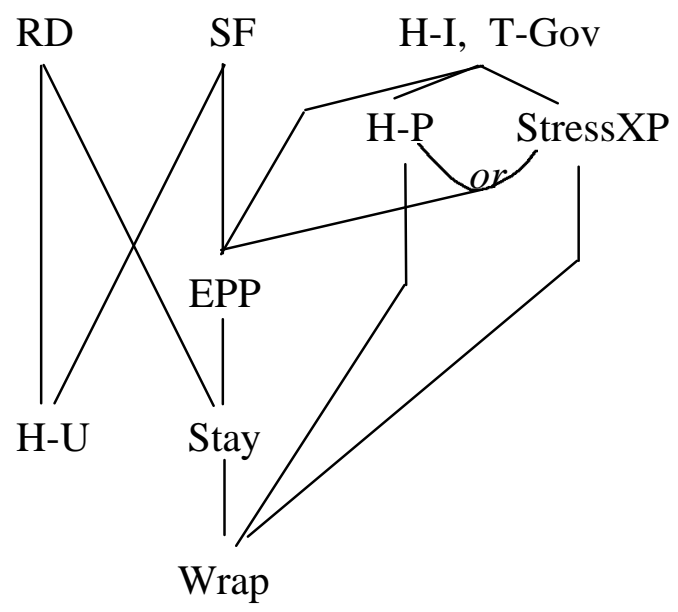

The chart also highlights the intermingling of prosodic and syntactic constraints, supporting a model of the syntax-prosody interface where constraints are ranked individually rather than as constraints blocks.

\subsubsection{Focus Fronting and Focus In-situ}

Can the above analysis be extended to Italian focus fronting and focus in-situ? While an exhaustive analysis requires a paper of its own, in this section I propose contra Rizzi (1997) that these patterns are actually instances of rightward focus followed by right dislocation fully analogous to the right dislocation cases examined in $\$ 3.4$ above.

This radical hypothesis has the theoretical merit of providing a unified analysis valid across all observed paradigms. It also finds significant preliminary support in Vallduvì (1992) and Frascarelli (2000) who showed that constituents following focus always present the prosodic and syntactic hallmarks of right dislocated phrases. Frascarelli showed that post-focus material is always wrapped in an I-phrase of its own, as is typical of right dislocated phrases. Vallduvì noted that arguments and adjuncts following focus are always freely ordered, again as is typical of right dislocated constituents. Vallduvì's test is applied to Italian focus fronting in (49) and to focus insitu in (50) below. In both cases the constituents following focus can occur in any order and are all preceded by an intonational fall and an optional pause. (Focus is marked by the subscript 'f', main stress in capital. ${ }^{15}$ )

15 Here main stress always falls on the fronted focus but according to Calabrese (p.c.) it is also possible to stress the unfocused verb that follows a fronted focused object carrying local pitch accent. The answer to 'What did Carl buy?' would then be as in (i) below.

(i) Un libro f ha COMPRATO, Carlo Context: What did Carl buy?

a book, has bought, Carl 
(49) Un LIBRO, a Maria, Gianni, ha regalato. a book, to Mary, John, has donated

John has given a BOOK to Mary

(50) Ha regalato un $\mathrm{LIBRO}_{\mathrm{f}}$, Gianni, a Maria. has donated a book, John, to Mary

John has given a BOOK to Mary
Context: What has John given to Mary?

Context: What has John given to Mary?

The right dislocation analysis is also supported by the study of negative polarity items. In Italian, negative polarity items (NPI) within VP must be licensed by a neg-marker in $\mathrm{I}^{\mathrm{o}}$ or by a negative subject in specIP c-commanding them (Laka 1990, Zanuttini 1991). Yet licensing is interrupted whenever postverbal NPIs are preceded by focus, precisely as predicted if the NPI have been right dislocated and therefore placed outside the licensing domain of their licenser (Samek-Lodovici 1996b).

Consider for example sentence (51) below where an indirect object NPI follows a focused object. Under the focus in-situ analysis the NPI should be grammatical because nothing prevents its licensing by the sentential neg-marker in $\mathrm{I}^{\mathrm{o}}$. Under the right dislocation analysis instead the same NPI lies outside the licensing domain of the neg-marker and the sentence is correctly predicted to be ungrammatical (consider again the position of right dislocated constituents in structure (44) above). Note that focus does not inherently interfere with NPI-licensing: when focus is rightmost, as in (52), NPI-licensing of the preceding indirect object occurs successfully.

* Non ho dato le CHIAVI $\mathrm{f}$, a nessuno. not have.1sg given the keys to anybody

I did not give the KEYS to anybody

(52) Non ho dato a nessuno le CHIAVI f $_{\text {. }}$ not have.1sg given to anybody the keys

I did not give the KEYS to anybody

Context: What haven't you given to anybody?

The same argument applies to focus fronting. A negative subject can license a negative object under sentence-wide focus; see (53) below where negative concord between licenser and licensee ensures that the clause is not interpreted as a double negative. The same negative subject ceases to license the NPI object as soon as it is focused in sentence initial position as in (54). This is unexpected if the focused subject is fronted into the specifier of a focus projection above IP as claimed in Rizzi (1997), because in this case the subject would still c-command the negative object and should remain able to license it. Contrast this with the right dislocation analysis, where the entire IP-remnant 'ha visto nulla' is right dislocated and therefore no longer c-commanded by the focused subject. This leaves the NPI object unlicensed, correctly deriving the sentence ungrammatical status. Note that a non-negative object within the dislocated IP-remnant remains possible in (55), showing that no other factor but NPI-licensing is responsible for the ungrammaticality of (54).

(53) [Nessuno ha visto NULLA $]_{\mathrm{f}}$

Context: How is the murder investigation going?

nobody has seen anything

Nobody has seen anything

In my own idiolect leaving focus unstressed is severely ungrammatical and I could not find any informants who finds Calabrese's contour acceptable. For this reason, I prefer to delay any comments until more is known about the varieties of Italian that allow for it. 
(54)

* NESSUNO , ha visto nulla nobody has seen anything NOBODY has seen anything

(55) NESSUNO , ha visto l'assassino nobody has seen the murderer NOBODY has seen the murderer
Context: Who has not seen anything?

Context: Who has seen the murderer?

The right dislocation analysis for (54) above also predicts that the negative object can be licensed again by inserting a negative marker within the dislocated phrase, a prediction confirmed by (56) below. As expected, (56) unlike (53) above is interpreted as a double negative because right dislocation severed the c-command relation between the initial subject and the following IPremnant necessary for negative concord.

(56) NESSUNO $_{\mathrm{f}}$, non ha visto nulla nobody not has seen anything NOBODY has seen nothing (Everybody saw something)

Under the proposed right dislocation analysis 'focus fronting' and 'focus in-situ' are purely descriptive terms characterizing structures where right dislocation is word order vacuous, giving the impression of focus fronting and focus in-situ. If this is correct, the conflict-based analysis that I have proposed here accounts for Italian new information focus in its entirety. All focus is pulled rightmost by the prosodic constraints and $\mathrm{SF}$, except for the quantifier and right dislocation cases where focus only occurs as rightward as consistent with T-Gov and RD.

\section{Constraint Conflict and Crosslinguistic Variation}

Constraint reranking determines new resolutions of the underlying constraint conflicts, giving rise to crosslinguistic variation. Unlike parameters, which can set properties specific to a particular language independently from UG constraints, constraint reranking may at most affect which properties are prioritized among those already required by the constraints themselves (Grimshaw 1997). The range of possible variation is thus directly determined by the universal constraints of grammar.

Under this more restrictive theory of variation it becomes impossible to introduce language specific provisions such as Zubizarreta's [ $t$ prosodic visibility] parameter governing the visibility of unfocused constituents to stress-assignment in each specific language or Vallduvì's [ \pm plastic] parameter separating languages like Italian from those like English according to a stipulated degree of intrinsic flexibility in their syntax (Vallduvì 1991, 1992, Engdahl \& Vallduví 1994). As this section will show, these parameters are unnecessary. The syntax and prosody of Italian, English, and other languages are governed by the same invariant set of universal constraints and the differences in their focus paradigms follow from the different rankings assigned to these constraints.

\subsection{Focus in English: Syntax Affecting Prosody}

The analysis of English focus is particularly complex due to the pragmatic and thematic factors that may affect the final position of stress (see among others Bolinger 1972, Schmerling 1976, Gussenhoven 1983, 1984, Nespor \& Vogel 1989, Ladd 1996). Once we abstract away from these factors we observe that English, like Italian, assigns main stress rightmost in focus-neutral 
contexts, ${ }^{16}$ but unlike Italian it cannot focus its constituents rightward (with the exception of heavy-NP shift constructions to which I return in the next section,). Rather than having focus matching stress as in Italian, we observe main stress matching the canonical position of focused constituents even when they do not occur rightmost, see the examples below.

$$
\begin{array}{llll}
(\mathrm{x} & - & ) & \mathrm{I} \\
(\mathrm{x}) & (\overline{\mathrm{x}} & ) & \mathrm{P}
\end{array}
$$

$$
\mathrm{John}_{\mathrm{f}} \text { has laughed Context: Who has laughed? }
$$

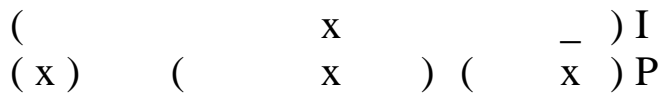

(58) John has given a book ${ }_{f}$ to Mary
Context: What has John given to Mary?

The apparently inflexible syntax and flexible prosody of English, which led Vallduvì to assign it the [-plastic] parametric value, follows from the higher rank enjoyed by the syntactic constraints EPP and Stay relative to the prosodic constraints H-I and Wrap. For example, the structure for focused subject in (57) above, repeated in (a) below, beats the Italian-like alternative (b) with a postverbal subject because satisfying EPP takes priority over satisfying H-I through a properly aligned I-phrase head.

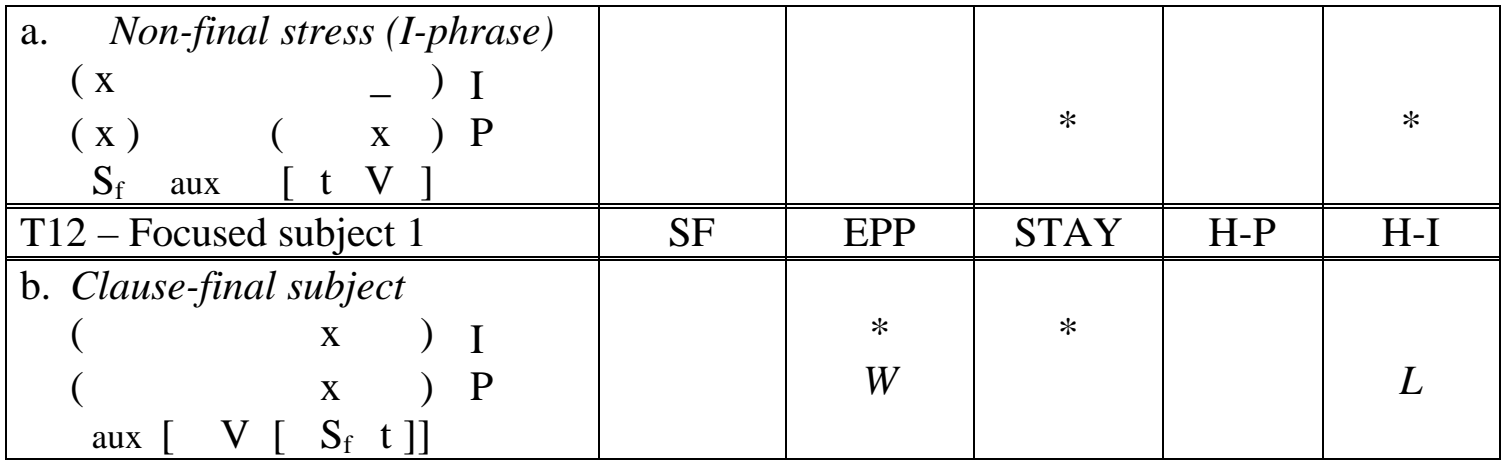

Main stress in turn is forced to fall on the focused preverbal subject by SF even though keeping stress rightmost as in (b) below would satisfy the lower ranked H-I.

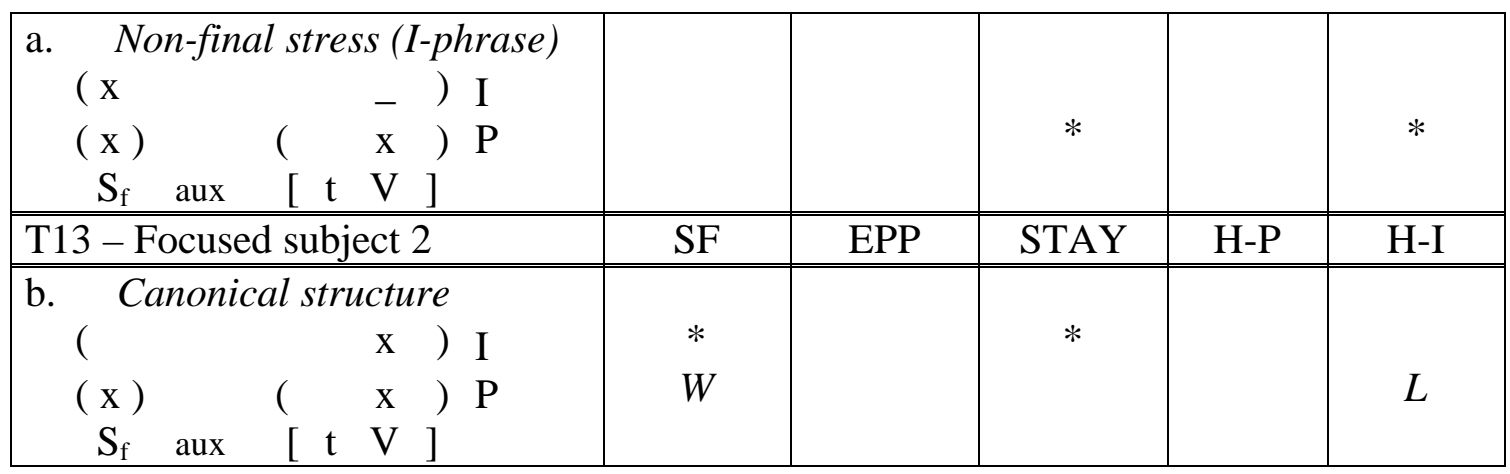

English preverbal focused subjects must also beat structure (b) below which avoids H-I and Stay violations by keeping the subject in specVP. This structure violates EPP, which was shown

16 Rightmost stress is viewed as the default pattern for English sentence-wide focus by a considerable body of literature, including Chomsky \& Halle (1968), Bresnan (1971, 1972), Liberman and Prince (1977), Ladd (1980, 1996), Rochemont (1986), Nespor \& Vogel (1986), Halle \& Vergnaud (1987), Hayes (1995), Selkirk (1995), Cruttenden (1997). 
to outrank H-I in T12 above and will be shown to outrank Stay in T18 below. This suffices to make (b) suboptimal. It also leaves us with no possible inference about the rank of H-P despite its being violated by (b) as well.

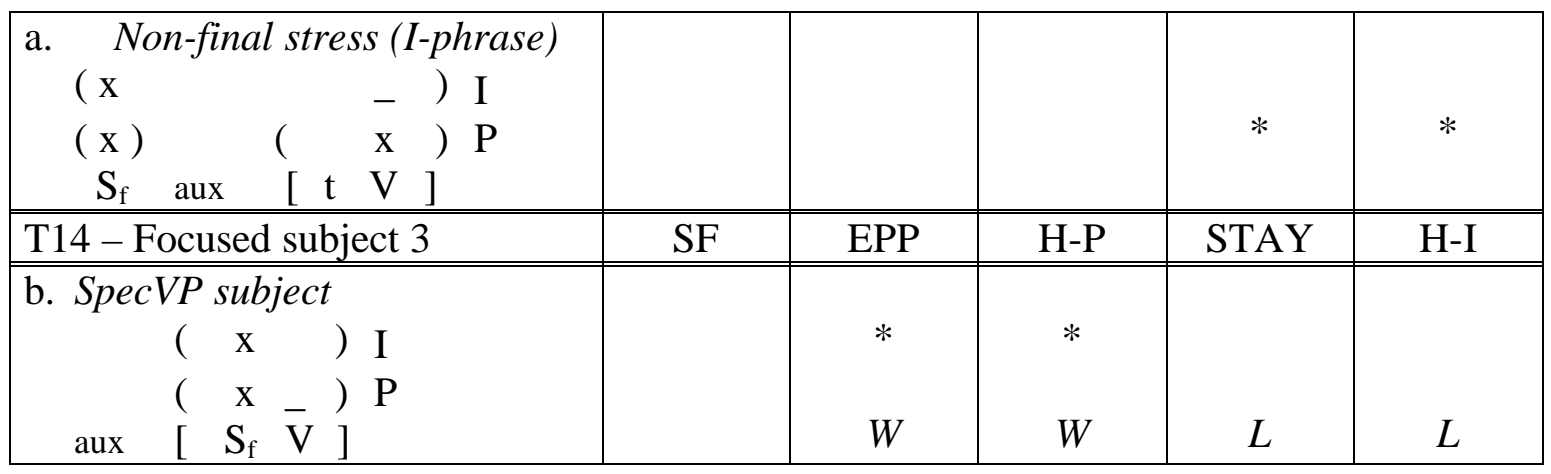

In English, Stay outranks prosodic constraints too. Consider the focused object in (a) below, corresponding to sentence (58) above. It beats the rightmost focus alternative in (b) which unlike (a) satisfies Wrap and H-I by wrapping verb and object in a single P-phrase and keeping a rightmost headed I-phrase. But (b) violates the higher ranked Stay more than (a) due to the scrambled indirect object and this is sufficient to make it suboptimal.

\begin{tabular}{|c|c|c|c|c|c|c|}
\hline 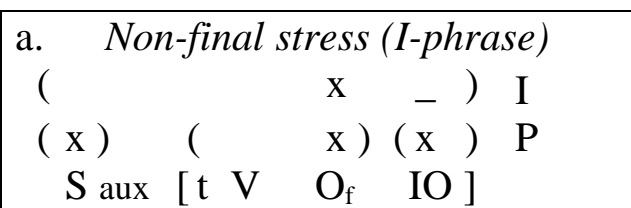 & & & $*$ & & $*$ & * \\
\hline T15 - Focused object 1 & SF & EPP & Stay & H-P & $\mathrm{H}-\mathrm{I}$ & Wrap \\
\hline 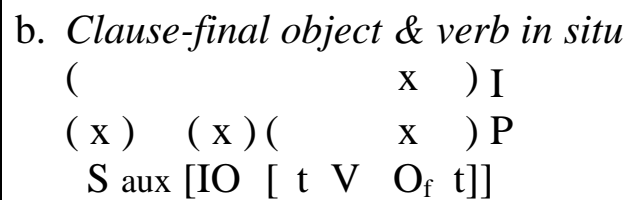 & & & $\begin{array}{c}* * \\
W\end{array}$ & & $L$ & $L$ \\
\hline
\end{tabular}

The H-I and Wrap violations of (a) can also be avoided by keeping the indirect object unmoved while wrapping the entire VP into a single P-phrase, as in (b) below. But (b) violates StressXP and H-P showing that one or both of these constraints outrank H-I and Wrap.

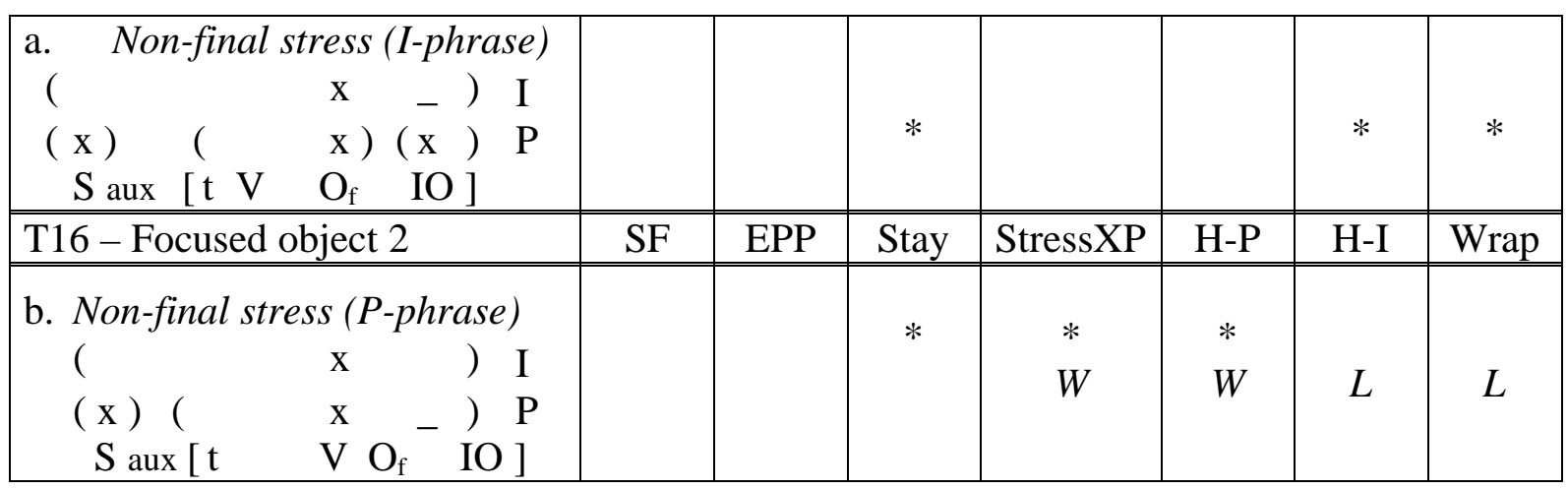

The ranking relations responsible for the basic properties of English focus do not prevent its convergence with Italian on SVO word order and rightmost stress under sentence-wide focus. This is exactly what is expected since this is the neutral context where prosodic and syntactic constraints do not conflict and are therefore satisfied independently from each other, eliminating any ranking-related effect. This is shown in the tableaux below where the canonical structure in 
(a) with SVO word order and rightmost stress competes with alternative (b) stressing the preverbal subject. SF is neutral between the two and therefore structure (b) loses because it violates $\mathrm{H}-\mathrm{I}$.

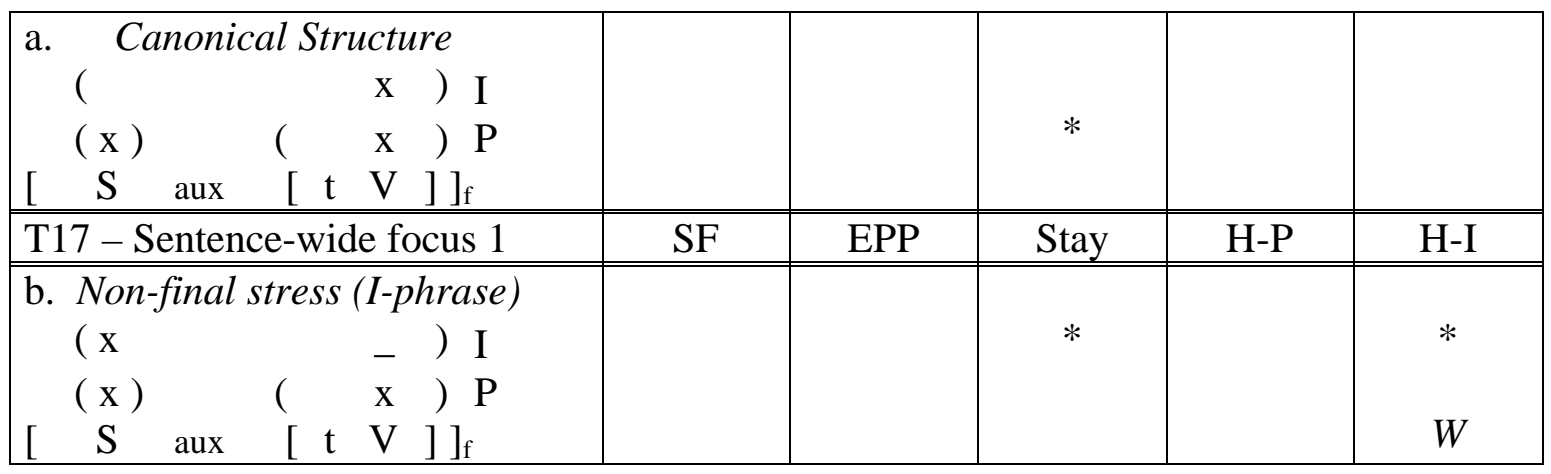

The neutral sentence-wide focus context also establishes the higher rank of EPP relative to Stay. Consider simple transitive clauses like (a) and (b) below. The SVO structure in (a) fails Stay because the subject moves to specIP. The specVP subject in (b) avoids this violation but violates EPP. It also violates Wrap because VP is no longer wrapped in a single P-phrase. Since Stay outranks Wrap (see T15 above) the ungrammaticality of (b) must follow from EPP >>Stay.

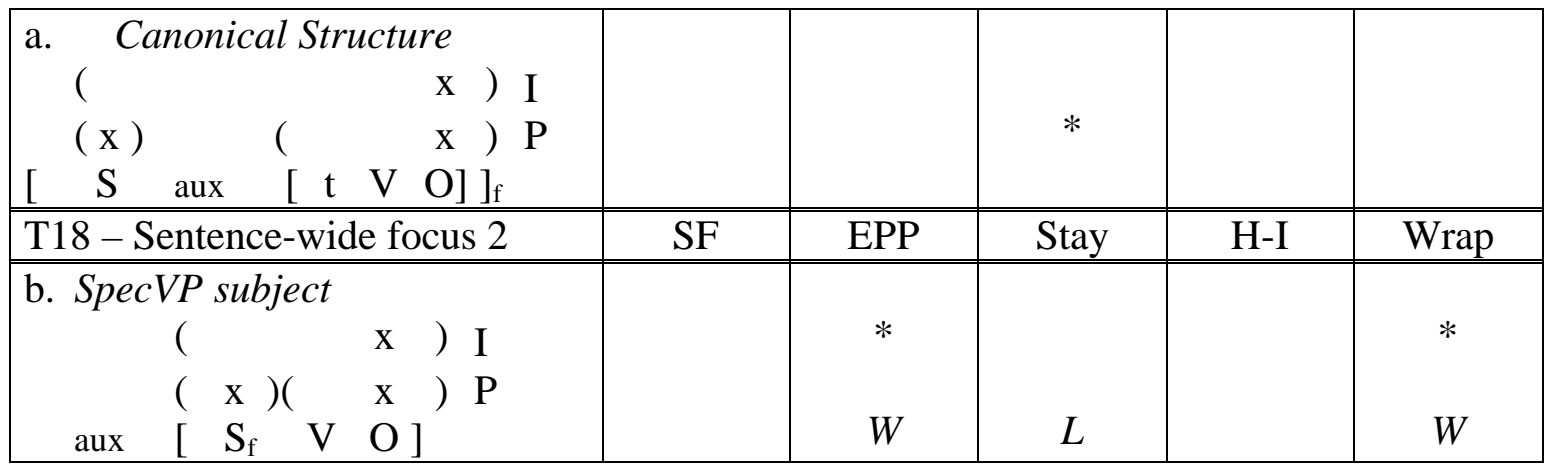

The ranking relations necessary for English focus follow below. ${ }^{17}$ Its apparently inflexible syntax follows from the higher rank of the syntactic constraints EPP and Stay relative to the

17 Prosodic destressing of unfocused constituents, involving actual effacement of prosodic structure, can be derived too provided that GEN is allowed to produce competitors with defective prosodic structures. For example, leaving the indirect object following a focused object prosodically unparsed as in (a) below provides better prosodic alignment for the I-phrase at the cost of StressXP, which is failed by the indirect object (see also Truckenbrodt 1995).

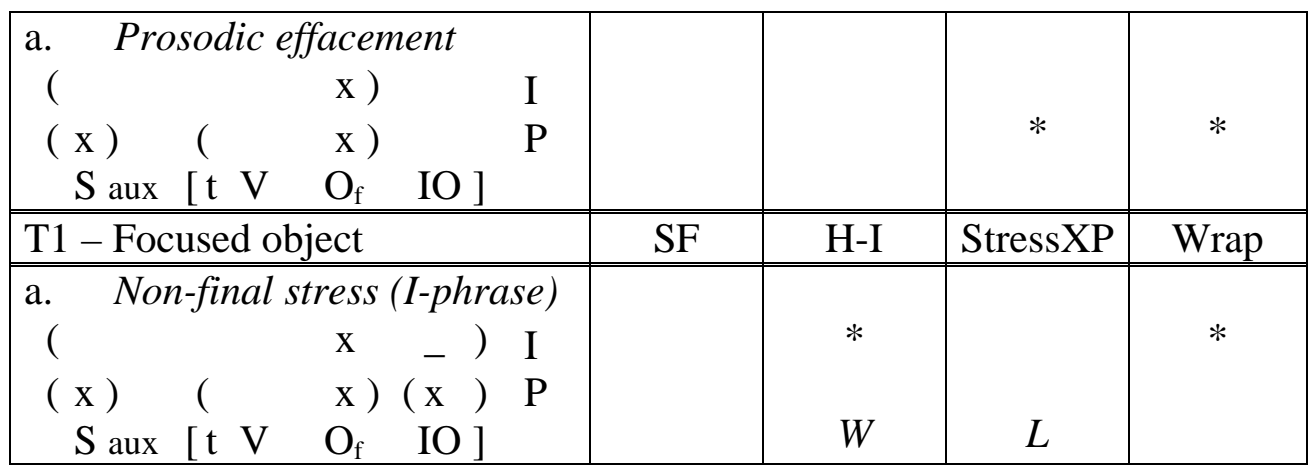


prosodic constraints H-I and Wrap. There is no need to redundantly stipulate it as an idiosyncratic and unexplainable parametric property of the language.

(59) English:

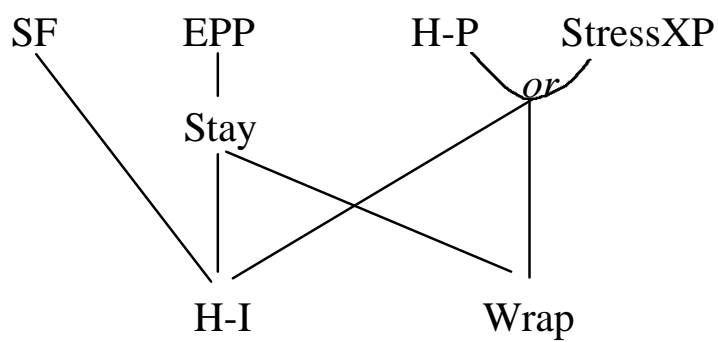

\subsection{Constraint Intermingling in French}

Is there any restriction on the possible ranking relations of syntactic and prosodic constraints? One interesting restriction is proposed in Szendröi (2001) who maintains that prosodic and syntactic constraints form two indivisible constraint blocks. Here I argue for the opposite view, claiming that intermingled prosodic and syntactic constraints can and do occur. The same conclusion is reached by Dehé (to appear) in her analysis of focus-induced word-order effects in English and German particle verbs.

A first instance of constraint intermingling already emerged from the analysis of Italian rightward focus in $\$ 3$ above where EPP and Stay occur sandwiched between the prosodic constraints H-I and Wrap. Constraint reranking predicts a second possible case of intermingling where H-I is ranked lower than EPP but higher than Stay. As discussed in detail below this ranking focuses subjects preverbally, as in English, but internal arguments postverbally, as in Italian. This pattern is attested in English heavy-NP shift, which optionally shifts focused objects but not focused subjects rightwards (Rochemont 1986, Rochemont \& Culicover 1990). ${ }^{18}$ The same pattern is also found in French, as described below.

Like English, French normally shows stress matching the canonical position of a focused constituent. For example, a stressed preverbal subject like (60) below is deemed acceptable or only slightly marginal as an answer to the question 'Who has won?', whereas the inverted subject in (61) is rejected as severely ungrammatical.
(60) FLORENCE $_{\mathrm{f}}$ a gagné
Context: Who has won?
Florence has won
(61) *Il a gagné FLORENCE it has won Florence

Context: Who has won?

Zubizarreta however noted that the acceptability of clause-final focus significantly improves when it affects the object of a ditransitive construction (Zubizarreta 1998:146-148). She observed for example that the clause-final object in (62) below is ungrammatical as an answer to a question focusing the entire VP like (63) but becomes marginally acceptable as an answer to a question focusing the object alone like (64).

18 The H-I > Stay ranking necessary for the analysis of heavy-NP shift contrasts with the Stay>>H-I ranking required for the in-situ focus pattern examined in $\$ 4.1$ above. This is consistent with the optional nature of heavy-NP shift under the assumption that optionality emerges from the co-existence of different constraint rankings within the same language. 
(62) Nous avons rendu à Marie son LIVRE we have returned to Mary her book

We returned her book to Mary

(63) What did you do?

(focusing the entire VP)

(64) What did you return to Mary?

(focusing the object)

The inflexible position of focused subjects parallels that of English subjects and like them follows from ranking EPP higher than H-I as shown in T19 below. The clause-initial subject in (a) violates H-I and Stay but satisfies the higher ranked EPP, making the clause-final subject alternative in (b) suboptimal.

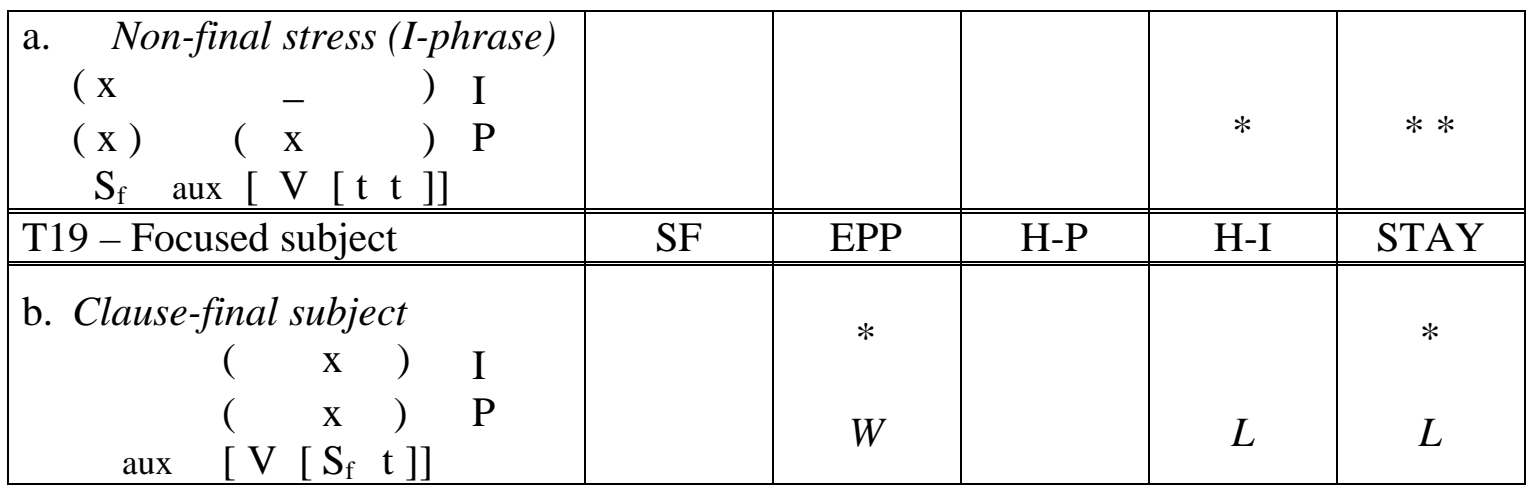

The flexible position of focused objects on the other hand parallels that of Italian internal arguments and like them follows from ranking H-I higher than Stay as shown in T20 below. Stranding the object in clause-final position as in (a) violates Stay but satisfies the higher-ranked $\mathrm{H}-\mathrm{I}$ and is thus preferred to leaving the indirect object in-situ as in (b). ${ }^{19}$

Once considered together T19 and T20 show that the focus pattern under scrutiny requires constraint intermingling, with prosodic H-I sandwiched between a higher EPP and a lower Stay.

\begin{tabular}{|c|c|c|c|c|c|c|}
\hline 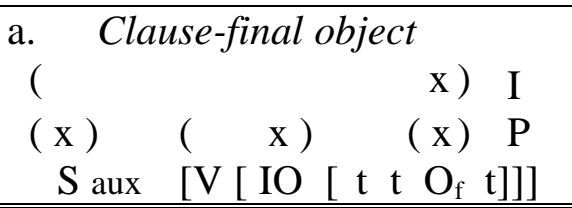 & & & & & $* * *$ & * \\
\hline T20 - Focused object 1 & SF & EPP & H-P & $\mathrm{H}-\mathrm{I}$ & STAY & Wrap \\
\hline 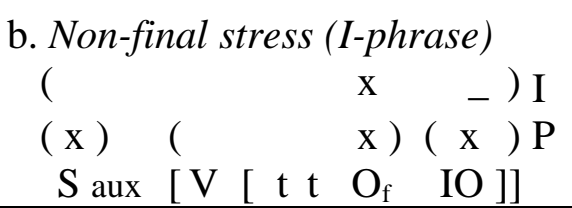 & & & & $W$ & $\begin{array}{c}* * \\
L \\
L\end{array}$ & $*$ \\
\hline
\end{tabular}

A second instance of constraint intermingling follows from considering structure (b) below which outperforms (a) on Stay and Wrap by wrapping the entire VP into a single P-phrase. Structure (b) violates StressXP and H-P and its suboptimal status indicates that either or both of these constraints outrank Wrap and Stay. But Stay outranks Wrap, and therefore syntactic Stay emerges both dominating and dominated by prosodic constraints.

${ }^{19}$ The lower rank of Stay relative to prosodic constraints is also suggested by Fery's analysis of French focus (2000) where enhancing the overall prosodic phrasing of a sentence is claimed to determine the topicalization and clefting of focused constituents despite the Stay violations induced by these operations. 


\begin{tabular}{|c|c|c|c|c|c|c|c|}
\hline 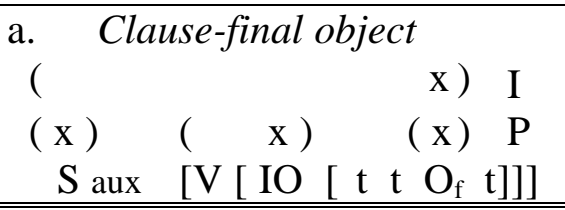 & & & & & & $* * *$ & $*$ \\
\hline T21 - Focused object 2 & $\mathrm{SF}$ & EPP & StressXP & $\mathrm{H}-\mathrm{P}$ & $\mathrm{H}-\mathrm{I}$ & Stay & Wrap \\
\hline b. Non-final stress (P-phrase $)$ & & & $*$ & $*$ & & $* *$ & \\
\hline 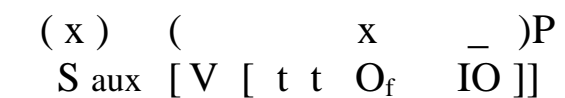 & & & $W$ & $W$ & & $L$ & $L$ \\
\hline
\end{tabular}

The remaining ranking relations for the focus pattern at issue have already been examined in T13 above for preverbal focused subjects (French raising past-participles do not affect the ranking relations there established) and in T6 and T7 above for clause-final focused objects. Once merged together with the relations established here they determine the chart below. Intermingling of prosodic and syntactic constraints is thus necessary to properly account for the variation in focus patterns observed across different languages.

(65) French partial clause-final focus:

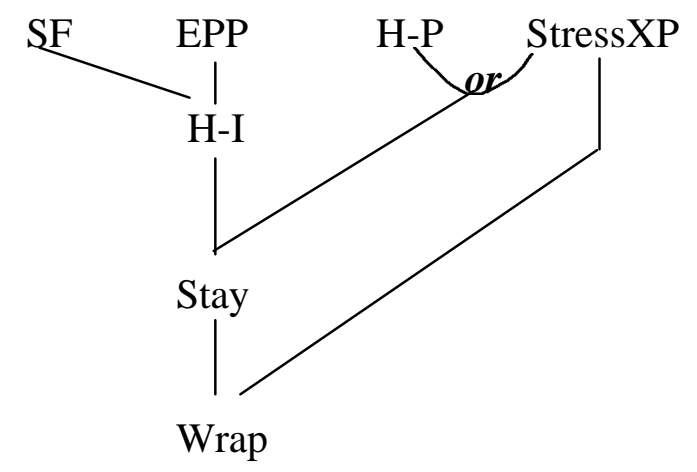

\subsection{Prosodic Effects in Bantu Languages}

The constraints underlying the Italian, English, and French focus paradigms examined above also determine the prosodic effects of focus in the Bantu languages Chi Mwi:ni, Chichewa, and Kimatuumbi analyzed in Truckenbrodt (1995, 1999). Except for the analysis of sentential prominence, to which I return in $\$ 4.3 .2$ below, the extension is straightforward because the prosodic constraints are fundamentally the same ones proposed by Truckenbrodt in his analysis.

As for the syntactic constraints, in all three languages they must be ranked sufficiently high in the hierarchy to ensure that the syntactic structure remains invariant across distinct focus contexts. Consequently the variation induced by focus is restricted to the prosodic layout and follows from the different rankings of the prosodic constraints Wrap, Stress-XP, and the constraint NonRec against recursive prosodic phrasing. Truckenbrodt's analysis is summarized in table (66) below showing the distinct prosodic structures assigned to a ditransitive VP by each language when the entire VP is focused. When StressXP is lowest, the whole VP is wrapped into a single P-phrase (Chichewa). When Wrap is lowest, all projections are phrasally stressed (Chi Mwi:ni). When NonRec is lowest, recursive P-phrases make it possible to wrap the VP and phrasally stress all projections (Kimatuumbi). H-P is omitted because satisfied across the board while 'XP' stands for NP or PP depending on the language. Evidence for the different prosodic structures is reviewed in Truckenbrodt $(1995,1997,1999)$. 


\begin{tabular}{|c|c|c|c|}
\hline (66) Focus neutral context & NonRec & Wrap & StressXP \\
\hline 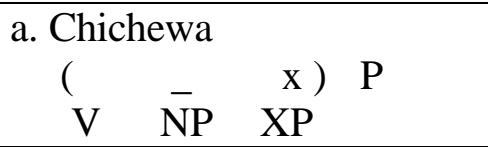 & & & $*$ \\
\hline 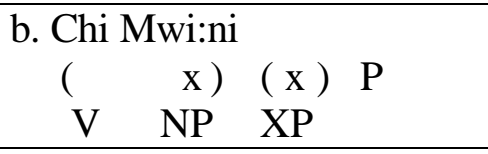 & & $*$ & \\
\hline 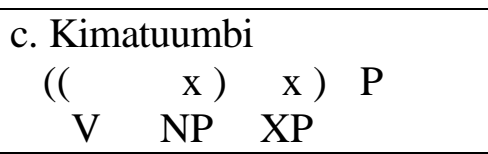 & * & & \\
\hline
\end{tabular}

The same rankings determine the effects of focus when it applies to specific constituents (Truckenbrodt 1995). To illustrate this point and examine the interactions with syntax in greater detail I examine the case of Chichewa at length in the two sections below.

\subsubsection{Focus Effects on P-phrasing in Chichewa}

Chichewa P-phrases are easily detected through the systematic vowel lengthening of the penultimate syllable of the P-phrasal head (Kanerva 1990a, 1990b). Under sentence-wide focus Chichewa's preverbal subjects are wrapped in a P-phrase of their own followed by a P-phrase for the entire verbal phrase, see the two examples below from Kanerva (1990a: 102, 104).
$(\mathrm{x})$

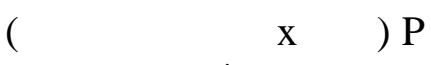
a. [ Fíisi anadyá ḿkáa $\left.{ }^{\mathrm{n} g o}\right]_{\mathrm{f}}$
Hyena ate lion
The hyena ate the lion
$(\mathrm{x}) \quad(\mathrm{x}) \mathrm{P}$
b. [ Kagaálu kaafa $]_{\mathrm{f}}$ small dog died
Context: sentence-wide focus
The small dog died

When focus targets specific constituents or syntactic heads, they occur in a P-phrase of their own and so do all following constituents; compare the focused VP in example (a) below, with a single P-phrase for the entire sentence, with the multiple P-phrases necessary for object and verb focus in examples (b) and (c) (Kanerva 1990a:98).
( [anaményá $\mathrm{X} \quad \mathrm{P}$ house with rock
$\mathrm{S} / \mathrm{he}$ hit the house with a rock
Context: VP focus
$(x)(x) P$
b. anaményá nyuú ${ }^{\mathrm{m}} \mathrm{ba}_{\mathrm{f}} \quad{ }^{\mathrm{n}} \mathrm{dí}$ mwáála s/he-hit house with rock

S/he hit the HOUSE with a rock

S/he HIT the house with a rock 
Let us start with the structure for VP focus in (68) above repeated in (a) below, where focus coincides with the entire sentence and gives rise to a single P-phrase. As mentioned above, this structure follows when StressXP is ranked lower than NonRec and Wrap (Truckenbrodt 1995), making the alternative prosodic layouts in (b) and (c) with multiple and recursive P-phrases suboptimal.

\begin{tabular}{|c|c|c|c|c|c|c|c|}
\hline 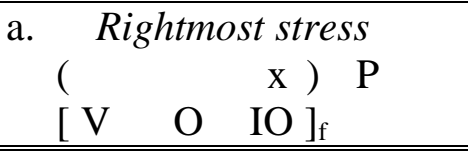 & & & & & & & * \\
\hline T22 - Sentence-wide focus & EPP & Stay & SF & H-P & NonRec & Wrap & StressXP \\
\hline $\begin{array}{l}\text { b. Multiple P-phrases } \\
\qquad \begin{array}{lll}(\mathrm{x}) & \mathrm{P} \\
{\left[\begin{array}{lll}\mathrm{V} & \mathrm{O} & \mathrm{IO}\end{array}\right]_{\mathrm{f}}}\end{array}\end{array}$ & & & & & & $\begin{array}{c}* \\
W\end{array}$ & $L$ \\
\hline 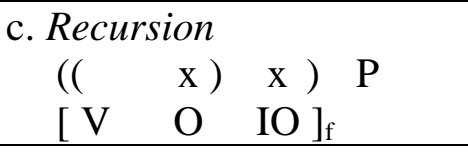 & & & & & $\begin{array}{c}* \\
W\end{array}$ & & $L$ \\
\hline
\end{tabular}

When the verb is focused, the verb and its following arguments are each wrapped on a P-phrase of their own as in (a) below. The associated violation of Wrap cannot be avoided without violating higher ranked constraints, as shown in (b)-(e). Using a single P-phrase for the entire VP as in (b) violates H-P (note that StressXP is here irrelevant since T22 proved it lower ranked than Wrap). Using recursive P-phrases to wrap the VP while stressing its arguments as in (c) violates NonRec. Using a rightmost stressed P-phrase as in (d) violates SF. Finally, shifting the arguments leftwards to leave a wrapped VP behind as in (e) violates Stay, showing this syntactic constraint ranked higher than prosodic Wrap and StressXP. The same holds for EPP, which we can consider higher ranked than Stay on the basis of the examples in (67) if their preverbal subjects have raised to SpecIP.

\begin{tabular}{|c|c|c|c|c|c|c|}
\hline $\begin{array}{l}\text { a. Exhaustive P-phrasing } \\
(\mathrm{x})(\mathrm{x})(\mathrm{x}){ }^{2} \mathrm{P} \\
{\left[\mathrm{V}_{\mathrm{f}} \mathrm{O} \quad \mathrm{IO}\right]}\end{array}$ & & & & & * & \\
\hline T23 - Focused verb 1 & Stay & SF & NonRec & $\mathrm{H}-\mathrm{P}$ & Wrap & StressXP \\
\hline $\begin{array}{l}\text { b. Leftmost stress } \\
\left.\begin{array}{lll}(\mathrm{x} & - & -\end{array}\right) \\
{\left[\begin{array}{lll}\mathrm{V}_{\mathrm{f}} & \mathrm{O} & \mathrm{IO}\end{array}\right]}\end{array}$ & & & & $\begin{array}{l}* * \\
W\end{array}$ & $L$ & $\begin{array}{l}* * \\
W\end{array}$ \\
\hline $\begin{array}{l}\text { c. Recursion } \\
((\mathrm{x}) \\
{\left[\begin{array}{lll}\mathrm{x} & (\mathrm{x})) & \mathrm{P} \\
\mathrm{V}_{\mathrm{f}} & \mathrm{O} & \mathrm{IO}\end{array}\right]}\end{array}$ & & & * & & $L$ & \\
\hline $\begin{array}{l}\text { d. Rightmost stress } \\
\left.\begin{array}{lll}( & \mathrm{x}\end{array}\right)^{\mathrm{P}} \\
{\left[\begin{array}{lll}\mathrm{V}_{\mathrm{f}} & \mathrm{O} & \mathrm{IO}\end{array}\right]}\end{array}$ & & $W$ & & & $L$ & * \\
\hline $\begin{array}{l}\text { e. Leftward shift } \\
\left(\begin{array}{ccc}\mathrm{x} & (\mathrm{x}) \quad(\mathrm{x} & \end{array}\right) \mathrm{P} \\
\mathrm{O} \quad \mathrm{IO}\left[\begin{array}{lll}\mathrm{V}_{\mathrm{f}} & \mathrm{t} & \mathrm{t}\end{array}\right]\end{array}$ & $\begin{array}{l}* * \\
W\end{array}$ & & & & $L$ & \\
\hline
\end{tabular}


Another possible competitor is given in (b) below, with a P-phrase for the focused verb and another for its arguments. This structure is readily eliminated because it fails StressXP on the object without bringing any benefits elsewhere. It shows, however, that Wrap cannot be gradient, i.e. violated once for each phrasal boundary cutting into the VP. This would assign (a) more Wrap violations than (b) and require the ranking StressXP $>>$ Wrap to eliminate (b), contradicting the ranking found necessary for the focus neutral case in T22 above.

\begin{tabular}{|l|l|l|l|l|c|c|}
\hline $\begin{array}{l}\text { a. Exhaustive P-phrasing } \\
(\mathrm{x}) \quad(\mathrm{x})(\mathrm{x}) \mathrm{P} \\
{\left[\mathrm{V}_{\mathrm{f}} \mathrm{O} \text { IO }\right]}\end{array}$ & & & & & & \\
\hline \hline T24 - Focused verb 2 & Stay & SF & H-P & NonRec & Wrap & StressXP \\
\hline \hline $\begin{array}{l}\text { b. Two P-phrases } \\
(\mathrm{x}) \quad(\mathrm{x}) \mathrm{P}\end{array}$ & & & & & $*$ & $*$ \\
{$\left[\mathrm{~V}_{\mathrm{f} \quad \mathrm{O}}\right]$} & & & & & & \\
\hline
\end{tabular}

Chichewa turns out to be very similar to English, with focus affecting prosody rather than syntax due to the high rank enjoyed by syntactic constraints. The difference lies in the relatively high rank of Wrap among the prosodic constraints, which as Truckenbrodt showed causes the wrapping of every constituent following focus. The corresponding chart follows below.

(69) Chichewa:

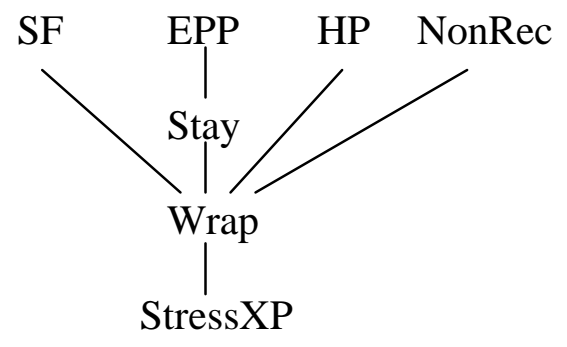

\subsubsection{Deriving Variation in Prosodic Culmination}

The above similarities between Chichewa and English contrast with their sharp divergence with respect to stress culmination. Chichewa is a non-culminant language, i.e. it does not always show a single main sentential stress. Instead the heads of any available phonological phrases emerge with the same stress, tone realization and intonation, providing no stress-related cue to what constituent is focused (Downing 2003, p.c.). For example, according to Downing (2003) the three sentences in (68) above differ only in their phonological phrasing but no phonetic correlate marks the focused constituent as more prominent than the constituents following it.

This important divergence could be accounted for via a culmination parameter governing the number of U-level prosodic peaks per sentence in each language. As is often the case with parameters this solution would describe the observed difference but not explain it. In this section I would instead like to explore an alternative analysis more firmly rooted in our current knowledge of the prosodic organization of the utterance.

At first sight, strict compliance with Selkirk's prosodic hierarchy would force us to identify every prosodic peak with the head of a corresponding U-phrase. Under this hypothesis example (c) in (68) above would have the representation below and culminant and non-culminant languages would differ in the number of U-phrases allowed for in a single utterance. 


$\begin{array}{lll}(\mathrm{x}) & (\mathrm{x}) & (\mathrm{x}) \mathrm{U} \\ (\mathrm{x}) & (\mathrm{x}) & (\mathrm{x}) \mathrm{I} \\ (\mathrm{x}) & (\mathrm{x}) & (\mathrm{x}) \mathrm{P} \\ \text { anaméenya } & \text { nyuú }{ }^{\mathrm{m}} \mathrm{ba} & { }^{\mathrm{n}} \text { dí mwáála } \\ \text { s/he hit } & \text { house } & \text { with rock }\end{array}$

S/he HIT the house with a rock

This representation however runs against Kanerva's description of Chichewa's I-phrases, which in the above case should encompass the entire utterance in a single I-phrase (Kanerva 1990a, 1990b). If this is correct, the final representation must reconcile the presence of multiple prominence peaks at the U-level with the single U-phrase projected by the single I-phrase proposed by Kanerva. This yields the representation below with a single I-phrase, a single U-phrase, but with each P-phrase allowed to project its head across all prosodic layers.

\begin{tabular}{|c|c|c|}
\hline $\mathrm{x}$ & $x$ & $x) U$ \\
\hline $\mathrm{x}$ & $\mathrm{x}$ & x ) \\
\hline $\begin{array}{c}\mathrm{x} \\
\text { enya } \\
\text { it }\end{array}$ & $\begin{array}{l}(\mathrm{x} \\
\text { nyuúm }^{\mathrm{m}} \mathrm{ba} \\
\text { house }\end{array}$ & )$^{\text {ndí mwáála }}\left(\begin{array}{l}\mathrm{x} \\
\text { with rock }\end{array}\right.$ \\
\hline
\end{tabular}

S/he HIT the house with a rock

This structure challenges the assumption that prosodic constituents have unique heads and that focus is more prominent than unfocused items. While these are fundamental issues that deserve further investigation it is worth examining what consequences the attempt to reconcile the properties of Chichewa with our knowledge of prosody has for the model proposed so far.

I assume that the multiple prosodic heads of (71) above are introduced by a stronger version of StressXP -call it StressXP $\mathrm{All}$ - requiring lexical projections to be stressed across all prosodic layers, I- and U-phrases included. StressXP $\mathrm{P}_{\text {All }}$ is violated once for each prosodic layer where a lexical projection is not matched by a prosodic head.

(72) Stress $\mathrm{XP}_{\text {All }}$.

A lexically headed XP must contain phrasal stress across all layers of the prosodic hierarchy.

Chichewa's lack of culmination in (71) then follows because Stress XP $\mathrm{P}_{\text {All }}$ outranks H-U and $\mathrm{H}-\mathrm{I}$, whereas the opposite ranking can be expected to hold in culminant languages. Structure (71), repeated in (a) below, satisfies StressXP $\mathrm{All}_{\text {All }}$ at the cost of multiple violations of $\mathrm{H}-\mathrm{U}$ and $\mathrm{H}-\mathrm{I}$ caused by the misaligned heads on the verb and the object, but the culminant alternative in (b), lacking multiple heads and therefore incurring less violations on $\mathrm{H}-\mathrm{U}$ and $\mathrm{H}-\mathrm{I}$, violates the higherranked Stress $\mathrm{XP}_{\mathrm{All}}$ four times (failures of Stress $\mathrm{XP}_{\mathrm{All}}$ are represented as '_'). 


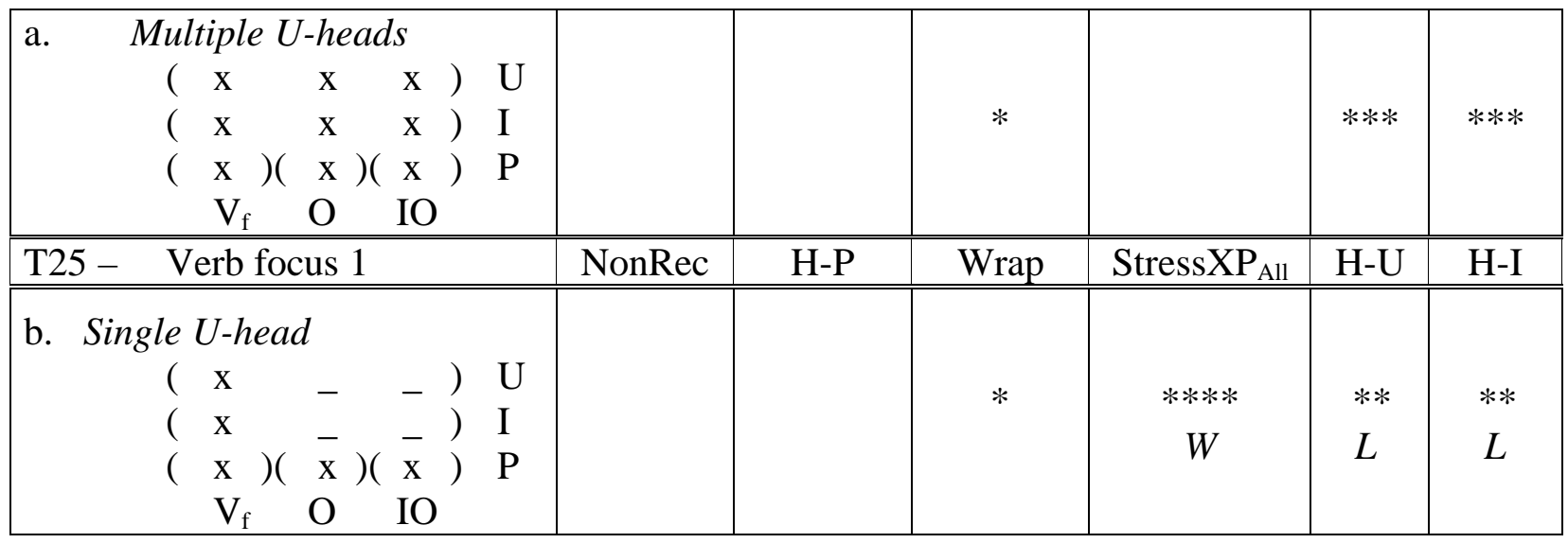

The same constraint ranking allows for the culminant U-phrase that emerges when the entire VP is focused in example (a) in (68) above. The corresponding structure in (a) below satisfies all head-alignment constraints as well as Wrap and NonRec, but it violates StressXP All $_{\text {three times }}$ because the object is left unstressed (the VP is stressed vicariously via its indirect object). As the tableaux shows, H-P, Wrap and NonRec block any competitors with less StressXP $\mathrm{P}_{\text {All }}$ violations than (a). For example, stressing the object across all layers as in (b) violates H-P because the Pphrasal stress is not aligned (H-I and $\mathrm{H}-\mathrm{U}$ are violated too but they are lower ranked than Stress $\left.\mathrm{XP}_{\text {All }}\right)$. Using two P-phrases to avoid the H-P violation as in (c) violates Wrap, and using recursion to satisfy both $\mathrm{H}-\mathrm{P}$ and Wrap at once as in (d) violates NonRec. By dominating Stress $\mathrm{XP}_{\text {All }}$ these three constraints ensure that the VP is parsed within a single P-phrase stressed on its rightmost item alone.

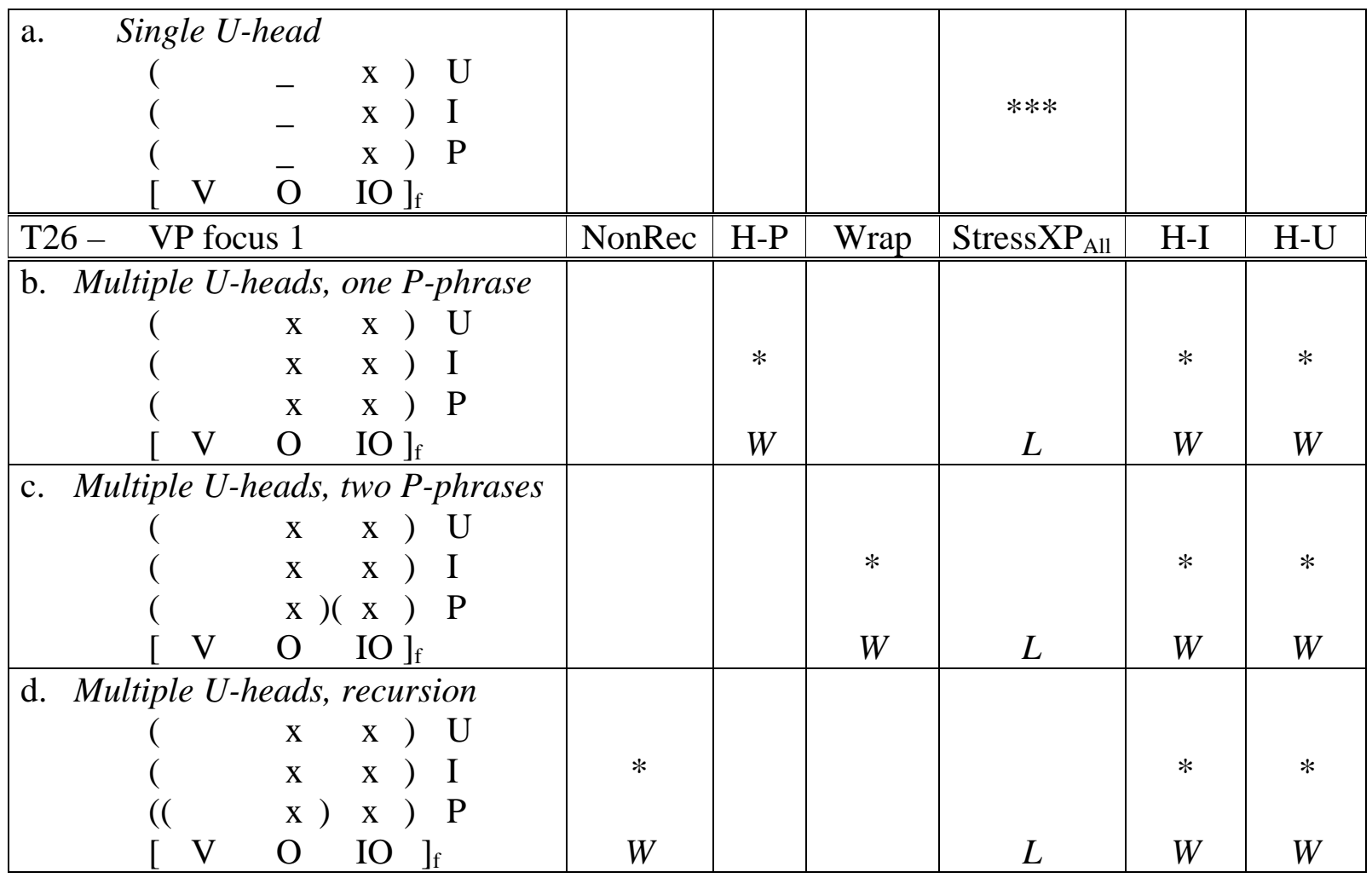

Chichewa's non-culminant structures also affect the relation between focus and prominence. The focused verb in (71) above fails to be the most prominent item as required by the SF constraint. At the same time it is precisely the need to make focus prominent that determines the changes in prosodic structure associated with focused verbs. This suggests that SF should be 
replaced by a weaker constraint $\mathrm{SF}^{\prime}$ demanding that focus receive the highest prosodic prominence but allowing focus to share it with other items where necessary.

The new SF' constraint is satisfied by (71), repeated again in (a) below, but failed by the structure in (b) with the focused verb unstressed. But (b) satisfies Wrap, H-P, and NonRec by wrapping the VP in a single rightmost headed P-phrase. Without SF', (b) would win because as we saw in T26 Wrap outranks StressXP ${ }_{\text {All }}$. Since (a) wins, SF' must outrank Wrap. ${ }^{20}$

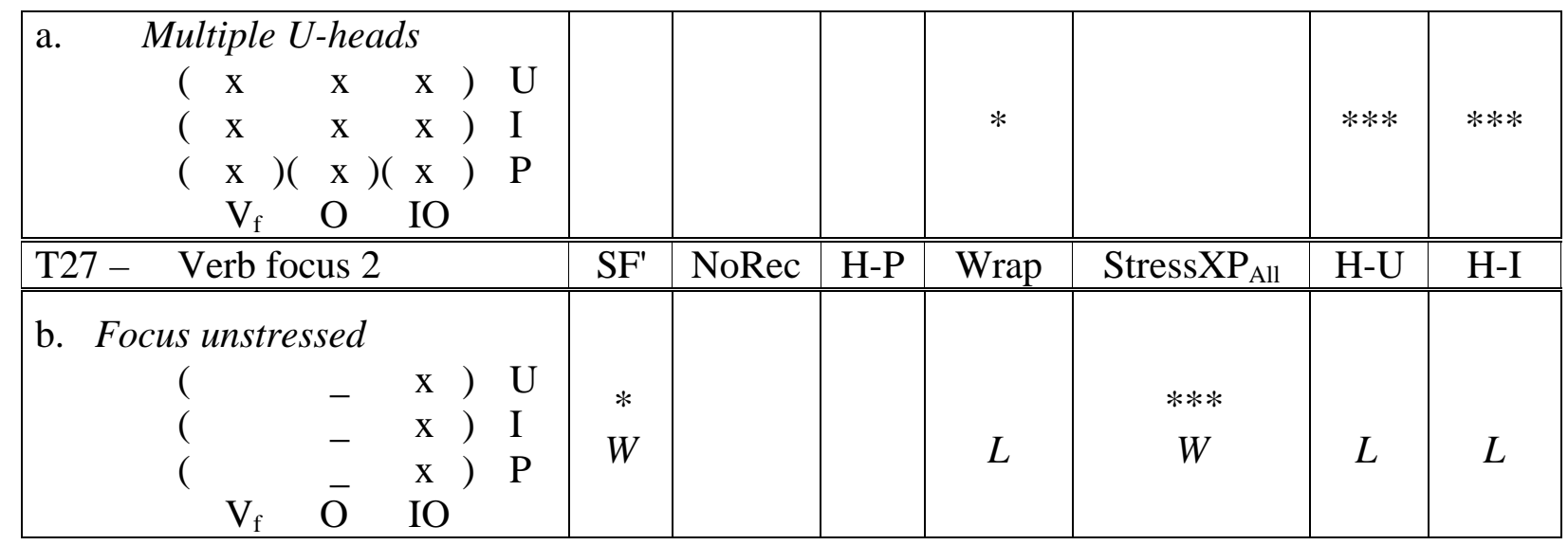

A final set of ranking relations is established in the tableaux below, showing Wrap dominated by H-P, NonRec, and Stay. Each of the competitors in (b)-(d) avoids the Wrap violation of the optimal structure (a) by a different strategy. Competitor (b) uses a single P-phrase, incurring H-P violations for each misaligned P-phrasal head. Competitor (c) uses recursion, failing NonRec. Competitor (c) uses syntactic leftward shift, violating Stay.

20 The optimalist readers might be tempted by the hypothesis of a gradient $\mathrm{SF}_{\text {Grad }}$ best satisfied when focus is the single most prominent item but also favoring shared highest prominence over non-highest prominence where necessary. This hypothesis is wrong. In T25 above $\mathrm{SF}_{\text {Grad }}$ favors (b) over (a), forcing the ranking StressXP $\mathrm{P}_{\text {All }}>>\left\{\mathrm{SF}_{\text {Grad }}, \mathrm{H}-\mathrm{I}, \mathrm{H}-\mathrm{U}\right\}$ to keep (a) optimal. At the same time Wrap outranks Stress $\mathrm{XP}_{\mathrm{All}}$, as shown by the competition below where $\mathrm{SF}_{\text {Grad }}$ is irrelevant. This yields the ranking Wrap $>>$ StressXP $\mathrm{P}_{\mathrm{All}}>>\left\{\mathrm{SF}_{\mathrm{Grad}}, \mathrm{H}-\mathrm{I}, \mathrm{H}-\mathrm{U}\right\}$ which incorrectly lets (b) beat the attested structure (a) in competition T27 above.

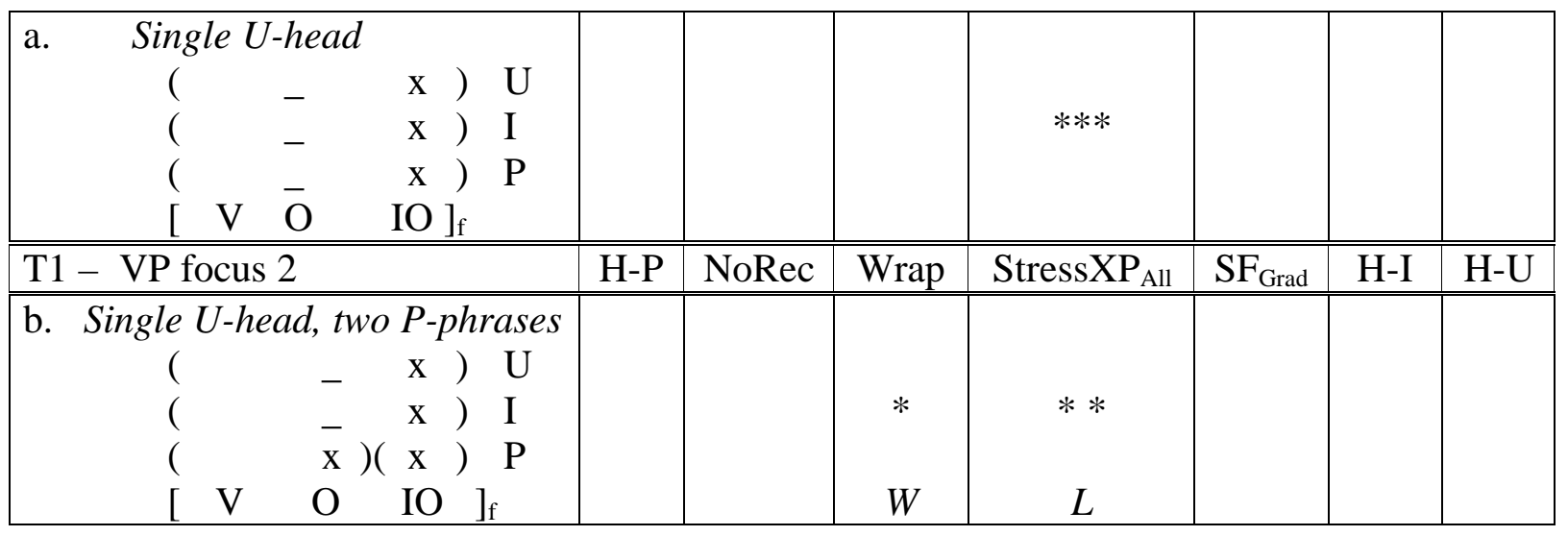




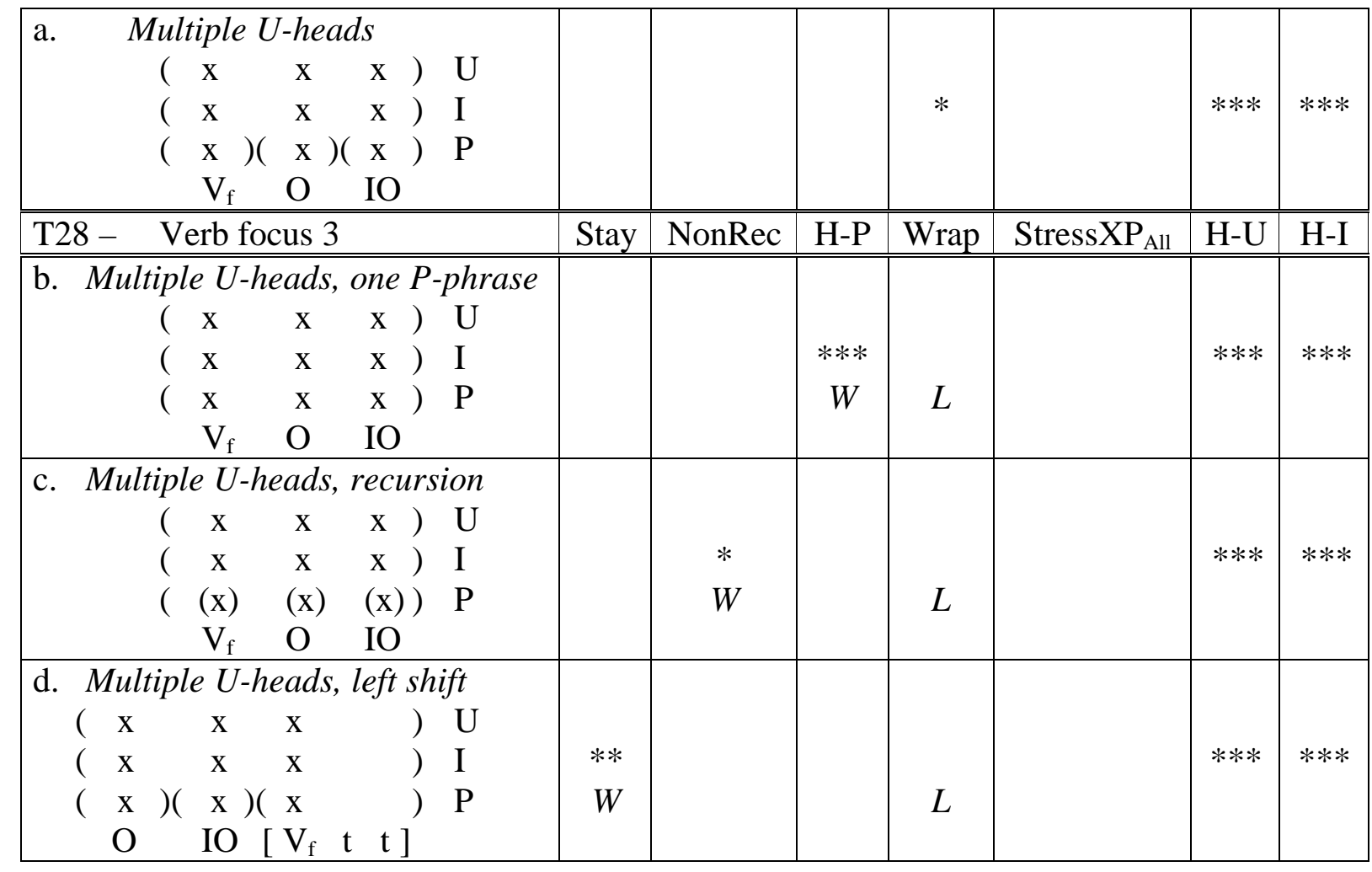

The final chart for Chichewa, including EPP $>>$ Stay motivated in the previous section, follows below. EPP and Stay dominate most prosodic constraints, while the higher position of Stress $\mathrm{XP}_{\text {All }}$ relative to $\mathrm{H}-\mathrm{I}$ and $\mathrm{H}-\mathrm{U}$ causes non-culminant structures in the relevant contexts.

(73) Chichewa:

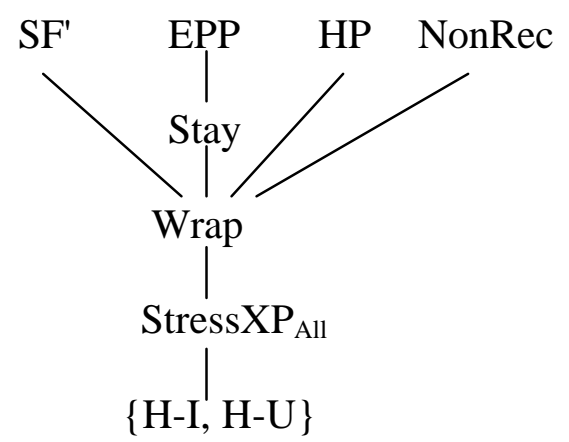

The analysis of Chichewa completes the analysis of the prosody-syntax interface. Crosslinguistic differences in the syntactic and prosodic expression of focus, potentially including differences in culmination too, follow immediately from a limited set of conflicting universal constraints. The next section turns to alternative accounts based on syntactic analyses of stress and discusses in detail some of their most problematic aspects.

\section{Syntactic Models of Stress and their Consequences}

As discussed in the introduction, minimalist analyses of rightward focus like Zubizarreta's 1998 must rely on a syntactic analysis of stress assignment to avoid contradicting the theoretical tenet that overt syntactic derivation logically precedes phonological expression (see also Brunetti 2003). As I argue in $\$ 5.1$ below, divorcing main stress from prosodic structure runs against the intrinsic similarity of main and secondary stress. Furthermore, main stress' sensitivity to complement selection in languages like German, which could appear to support a syntactic approach, has been shown to follow from the prosodic constraints by Truckenbrodt (1995), see 
$\$ 5.2$ below. Syntactic approaches also force an unnecessary parametric analysis of crosslinguistic stress systems which fails to capture the invariant nature of the prosodic constraints governing them, see $§ 5.3$,.

\subsection{The Challenge of Bengali}

There are strong theoretical and empirical reasons against modeling stress syntactically. To begin with, it cannot capture the distribution of main stress in a variety of languages. We already examined in $\$ 3$ Italian structures carrying non-final stress which defy a purely syntactic determination via the right-branching path of the syntactic tree. Even more problematic are languages that switch head-polarity across prosodic layers. One such language is Bengali, where I-phrases are right-headed but P-phrases are left-headed (Hayes and Lahiri 1991:55). Rightheaded I-phrases emerge most clearly in focus-neutral clauses like (77) below, where main stress falls on the head of the rightmost available P-phrase.

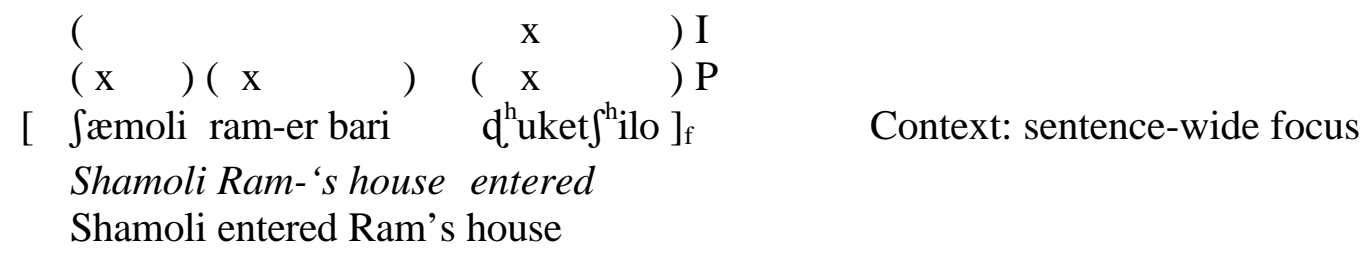

Left-headed P-phrases become visible when specific constituents are focused, as is the case with the focused object in the example below. As in English, main stress falls on the focused object, but the head of its P-phrase occurs leftmost rather than rightmost (all examples come from Hayes \& Lahiri, 1991:56. Some of the original symbols have been replaced with the corresponding IPA symbols).

$$
\begin{aligned}
& \left(\begin{array}{lll}
x & x & \\
x & )(x & ) I
\end{array}\right. \\
& \text { Sæmoli [ram-er bari }]_{\mathrm{f}} \mathrm{d}^{\mathrm{h}} \text { uket } \int^{\mathrm{h}} \text { ilo } \quad \text { Context: focused object }
\end{aligned}
$$

Shamoli entered Ram's house

A second set of examples is supplied in (79) and (80) below (Lahiri, p.c.). Example (79) occurs under sentence-wide focus either as an out-of-the-blue declarative or as the answer to a question like 'what happened?' and main stress is again rightmost in the I-phrase. When the object is focused by a question like 'what did you bring today?' main stress shifts to the leftmost item of the object's P-phrase, as in (80), confirming their left-headed nature. (The prosodic structure of (79) was assigned on the basis of the primary and secondary stress pattern supplied by Lahiri (p.c.) whereas for (80) see Hayes \& Lahiri 1991:62. For an OT-analysis of Bengali's P-phrasing see Truckenbrodt 1997:21.)

$$
\left(\begin{array}{rrr}
(x) & x & ) I \\
(x & (x) P
\end{array}\right.
$$

[Ad3 ami radza-r t th obi-r dzonno taka anlam $]_{\mathrm{f}}$ today I King's pictures-gen. for money brought

Today, I brought money for the King's pictures 

$(x)$
$(\mathrm{x} \quad)(\mathrm{x}$

(80) Ad3 ami [radza-r t thobi-r dzonno taka $]_{\mathrm{f}}$ anlam today I King's pictures-gen. for money brought

Today, I brought money for the King's pictures
Context: focused object

The above examples show that main stress is sensitive to P-phrasal prominence because it always falls on the head of the relevant P-phrase. This supports the prosodic analysis of stress adopted here where stress is determined by the accumulation of prosodic heads across prosodic levels. A syntactic model of Bengali stress would have to be sensitive to the very same prosodic domains from which it is assumed to be divorced, allocating prominence to the rightward branches of the syntactic tree while within the domain of the I-phrase, but switching to leftward branches when reaching the domain of the relevant P-phrase. This defeats the very purpose of a syntactic theory of stress because the algorithm would once again require access to post spell-out prosodic structures.

The tight relation between main stress and prosodic structure also emerges when comparing main and secondary stress. Both types of stress emerge from the stacking of prosodic heads across prosodic layers and are therefore described by the same empirical generalizations. If main and secondary stress are respectively syntactically and prosodically assigned these similarities become a mystery. For example, the words carrying secondary stress under sentence-wide focus in the above Bengali examples always become the ones carrying main stress when the corresponding constituent is focused. This is expected under the prosodic analysis followed here but becomes a coincidence if main and secondary stress are unrelated phenomena as for example maintained in Zubizarreta (1998).

The same reasoning applies to the stress systems of other languages. We have already seen the case for Italian at the end of $\$ 3.4$ above while an example for English is illustrated by the two sentences below: the word in the subject carrying secondary stress under sentence-wide focus in (81) is the one carrying main stress when the subject is focused in (82).

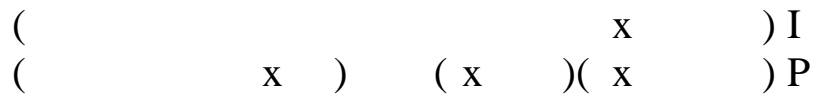
[The order to attack was issued yesterday $]_{\mathrm{f}} \quad$ Context: What happened?

$$
\begin{aligned}
& (\quad x \quad) \text { I } \\
& \left(\begin{array}{llll}
\mathrm{x} & (\mathrm{x})(\mathrm{x}) \mathrm{P}
\end{array}\right.
\end{aligned}
$$

$[\text { The order to attack }]_{\mathrm{f}}$ was issued yesterday Context: What was issued yesterday?

The shared nature of primary and secondary stress is also supported by the several analyses of word-stress retraction caused by stress-clash (Prince 1983, Nespor 1990, Selkirk 1984, 1986, Hayes 1995). All these analyses presuppose that secondary and main stress share the same representation in terms of cumulated grid marks. A syntactic approach to main stress would have to represent main stress prosodically in order to account for these phenomena but that makes its syntactic representation redundant.

In conclusion, syntactic models of stress are untenable because they cannot account for the distributional and representational aspects stemming from its prosodic nature. This in turn makes prosody-induced clause-final focus in Italian and other Romance languages a significant challenge for any framework where overt syntactic derivation logically precedes the deployment of prosodic structure. 


\subsection{The Adjunct/Argument Asymmetry}

While stress cannot be purely syntactically determined, we may wonder whether syntax may at least directly affect its distribution. Of particular interest is the observation that stress can be sensitive to the adjunct/argument distinction (Schmerling 1976, Gussenhoven 1984, Selkirk 1984). For example in German head final clauses stress obligatorily falls on preverbal objects, see (83) below, but ignores preverbal adjuncts, see (84).

Ein Junge hat ein BUCH gelesen

a boy has a book read

A boy read a book

Ein Junge hat in einem Sessel GELESEN

a boy has in an armchair read

A boy has been reading in an armchair
Context: sentence-wide focus

Context: sentence-wide focus

Truckenbrodt (1995:234-244) shows that even this asymmetry follows from the constraints StressXP and Wrap (but see Büring \& Gutierrez-Bravo 2002 for some interesting exceptions). As we saw in $\$ 2.4$ these constraints distinguish between complements and adjuncts. Parsing the VP in (83) above into a single P-phrase headed on the object satisfies Wrap and StressXP; the phrasal stress on the object eventually becomes the main stress of the entire sentence.

$$
\left(\begin{array}{ccc}
\mathrm{x} & - & ) \\
{[\mathrm{vP}} & \mathrm{Obj} & \mathrm{V}
\end{array}\right]
$$

StressXP and Wrap satisfied

In contrast, the VP-adjoined adjunct of (84) is wrapped on a P-phrase of its own, as in (86) below. It is the phrasal stress of the rightmost P-phrase, which contains the verb alone, that eventualy becomes the main stress of the sentence.

$$
\begin{array}{ll}
\left(\begin{array}{c}
\mathrm{X} \\
{[\mathrm{vp}}
\end{array}\right) & (\mathrm{x}) \mathrm{P} \\
&
\end{array}
$$

\section{StressXP and Wrap satisfied}

The adjunct/argument asymmetry thus follows from the concomitant action of Wrap and StressXP. It is only visible, however, in languages that rank StressXP and Wrap sufficiently high. In particular, while the adjunct prosodic structure in (86) satisfies all prosodic constraints and is thus favored independently of any prosody-internal ranking, the prosodic structure for arguments in (83) above requires Wrap and StressXP to dominate H-P, else H-P rules out the left-headed P-phrase in (85). The conflict is shown in T29 below, where non-final stress in (a) requires Wrap and StressXP to outrank H-P else stress falls rightmost as in (b) and (c). 


\begin{tabular}{|c|c|c|c|c|c|c|}
\hline 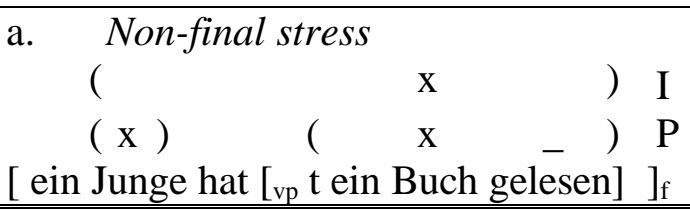 & & * & & & & $*$ \\
\hline T29 - Selected argument & EPP & Stay & Wrap & StressXP & H-I & $\mathrm{H}-\mathrm{P}$ \\
\hline 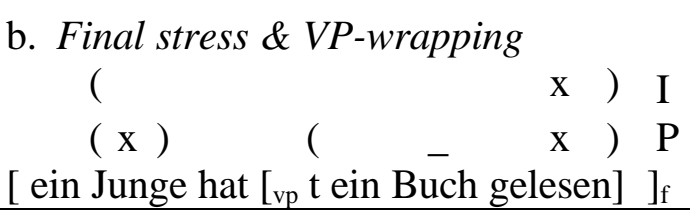 & & * & & * & & $L$ \\
\hline 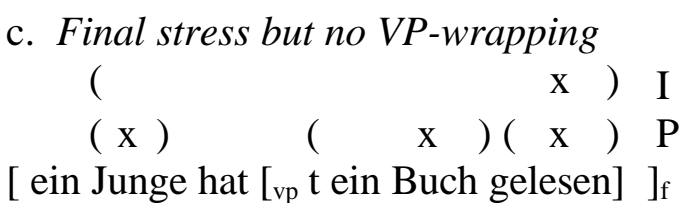 & & * & * & & & $L$ \\
\hline
\end{tabular}

Changing the ranking effectively prevents Wrap and StressXP from assigning prominence to non-final arguments. For example, in the Italian clause in (87) below the subject in specIP shares the same projection of the lexical verb in $\mathrm{I}^{\mathbf{0}}$ much like the object does with the verb in the German example (83) above, yet the subject receives its own P-phrase and stress remains final.

$$
\begin{aligned}
& (x) \text { I } \\
& \left(\begin{array}{ll}
\mathrm{x} & )(\mathrm{x}) \mathrm{P}
\end{array}\right. \\
& \text { Gianni mangerà Context: sentence-wide focus. } \\
& \text { John eat.FUT.3sg } \\
& \text { John will eat }
\end{aligned}
$$

This prosodic structure follows because Italian ranks H-P higher than Wrap. This penalizes

\begin{tabular}{|c|c|c|c|c|c|}
\hline 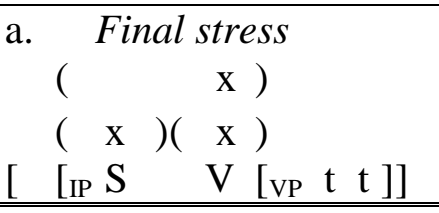 & $\begin{array}{l}\mathrm{I} \\
\mathrm{P} \\
]_{\mathrm{f}}\end{array}$ & & & & $*$ \\
\hline T30 - Finite verb & & $\mathrm{H}-\mathrm{P}$ & StressXP & $\mathrm{H}-\mathrm{I}$ & Wrap \\
\hline 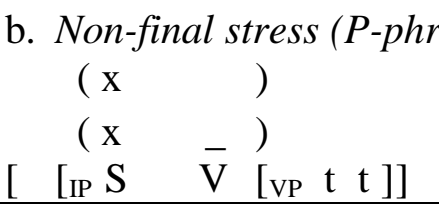 & $\begin{array}{l}\text { ase) } \\
\mathrm{I} \\
\mathrm{P} \\
]_{\mathrm{f}} \\
\end{array}$ & $W$ & & & $L$ \\
\hline 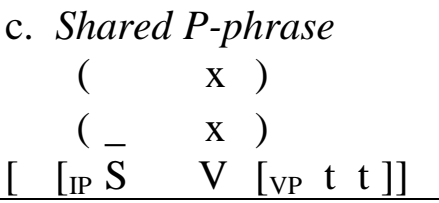 & $\begin{array}{l}\text { I } \\
P \\
]_{\mathrm{f}}\end{array}$ & & $W$ & & $L$ \\
\hline
\end{tabular}
wrapping subject and verb into a single subject-headed P-phrase, making the alternative in (b) below suboptimal. Italian also ranks StressXP above Wrap, as already established in $\$ 3.2$ above; this forces subjects into a P-phrase of their own in order to get phrasal stress and militates against having a single verb-headed P-phrase like the one in (c) below.

In conclusion, syntactic selection does play a role in the assignment of stress but only indirectly so by affecting the assessment of Wrap and StressXP and only in languages with the appropriate ranking relations. Moreover, the main effects of syntactic selection do not require a syntactic theory of stress and follow naturally from Truckenbrodt's constraints. 


\subsection{Describing Variation through Parameters}

Overlooking constraint conflict naturally leads to viewing crosslinguistic differences as language specific idiosyncratic properties eventually to be dealt with parametrically. Zubizarreta's analysis of stress is a case in point. It successfully identifies the properties shared by the Italian, German, English and French stress systems but must eventually account for the few remaining differences via language-specific properties and devices. Consequently, a first parameter is posited to govern whether stress is sensitive to syntactic selection (e.g. German stress is, Italian stress is not) while a second parameter is necessary to determine whether unfocused constituents are visible or invisible to the stress assignment algorithm (for example Italian constituents are assumed to be visible but not English ones).

The problem with parameters, even when cleverly designed, is that they introduce new properties not already mandated by UG-constraints. They thus constitute language-specific juxtapositions that can be changed at will without affecting the content of UG-constraints, effectively dissociating the theory of crosslinguistic variation from UG.

This dissociation is not supported by the empirical evidence at our disposal. Most proposed parameters turn out to affect the same linguistic properties governed by UG constraints even though there is no logical necessity for them to do so. The absence of much wilder and unrelated parameters might be welcome but it actually constitutes a distribution gap that demands an explanation.

The same issue does not apply to conflict-base analyses where crosslinguistic variation is directly and exclusively governed by the universal constraints of grammar. All linguistic properties follow from their content. Only constraint ranking remains parametric but it can never introduce a property or device not already required by UG-constraints. It is this property that made it possible to analyze different focus and stress paradigms as distinct resolutions of conflicts that are inherent to UG-constraints alone, thus dispensing with any language-specific property or device.

\section{Conclusions}

The diverging focus paradigms from Italian and English presented at the outset of this study are no longer puzzling: both languages share the same fundamental constraints for prosodic and syntactic representations but their different rankings determine divergent solutions for the problem of how to match stress with focus. The same constraints also account for the complex internal articulation of the Italian paradigm, for additional focus paradigms in French and Chichewa, and for specific prosodic properties in Chi Mwi:ni, Kimatuumbi and German.

The only constraints directly pertinent to the prosody-syntax interface are Wrap and StressXP -or possibly Stress $\mathrm{XP}_{\mathrm{All}}-$ which set minimal conditions over the mapping of syntactic structures into prosodic phrases. All other constraints refer to the sole syntactic or prosodic aspects of linguistic representations. The analysis thus supports a modular view of syntax and prosody where interface effects follow from their conflicting demands and the associated resolutions determined through constraint ranking.

The analysis has also shown that syntactic and prosodic constraints can and do intermingle. This diverges from Szendröi's (2001) hypothesis grouping them into separate constraint blocks. It is perhaps worth stressing that constraint intermingling does not affect modularity. Modularity pertains to the definition of the constraints whereas intermingling concerns only their ranking. Consequently intermingling only affects the range of possible solutions for any conflict involving prosodic and syntactic constraints. A ban on intermingling eliminates all solutions determined by 
intermingled rankings and thus reduces the range of crosslinguistic variation, but it cannot have any effects on the degree of modularity of the analysis. ${ }^{21}$

Before concluding we may briefly consider whether an analysis of this kind can be extended to additional languages. In many ways this effort is already under way and the reader may look at the OT-analyses respectively proposed for aspects of the focus paradigms of German, Spanish, Hungarian, Italian, and English in Büring (2001, 2002, 2003), Büring \& Gutierrez-Bravo (2002), Szendröi (2001, 2002), and Dehé (to appear). A more fundamental question is whether the analysis can be extended even to tone and pitch-accent languages lacking accentual stress or with lexically specified pitch-accents. Ladd (2001) notes that even in these languages it could be argued that stress is present and identified via intonational cues to local prominence or emphasis, mentioning how Chinese and Japanese may signal local emphasis by local widening of the overall pitch range. Some of these languages can also signal intonational boundaries via specific tones, as is for example the case in Chinese and Thai (Ladd, 2001), or use increased duration to signal contrastive focus, as claimed for Bejing Mandarin by Chen (2002). This raises the interesting possibility that these languages differ more in the phonetic correlate of prosodic prominence rather than in the prosodic structure proper and that once this difference is better understood these languages too could undergo the kind of analysis proposed in this study.

\section{References}

Ackema, Peter, and Ad Neeleman. 1998. WHOT?. In Pilar Barbosa, Danny Fox, Paul Hagstrom, Martha McGinnis, and David Pesetsky (eds.), Is the Best Good Enough. MIT Press, Cambridge, MA, pp. 15-34.

Ackema, Peter and Ad Neeleman (2002). Effects of Short-Term Storage in Processing Rightward Movement. In Sieb Nooteboom, Fred Weerman, Frank Wijnen (eds.), Storage and Computation in the Language Faculty. Kluwer, Dordrecht, pp. 219-256.

Alexiadou, Artemis, and Elena Anagnostopoulou 1999. EPP without Spec, IP. In David Adger,

Susan Pintzuk, Bernadette Plunkett, George Tsoulas (eds.), Specifiers, Minimalist Approaches. Oxford University Press, Oxford, pp. 93-109.

Antinucci, Francesco and Guglielmo Cinque. 1977. Sull'ordine delle parole in Italiano: l'emarginazione. Studi di Grammatica Italiana, Vol. VI, 121-146.

Bakovic, Eric. 1998. Optimality and Inversion in Spanish. In Pilar Barbosa, Danny Fox, Paul Hagstrom, Martha McGinnis, and David Pesetsky (eds.), Is the Best Good Enough. MIT Press, Cambridge, MA, pp. 35-58.

Belletti, Adriana. 1990. Generalized Movement. Rosenberg \& Sellier, Torino.

Belletti, Adriana and Ur Shlonsky. 1995. The Order of Verbal Complements: a Comparative Study. Natural Language and Linguistic Theory, Vol. 13, 489-526.

Bolinger, Dwight. 1972. Accent is Predicatble (If you're a mind reader). Language 48, 633-644. Bonet, Eulalia. 1990. Subjects in Catalan. In Lisa Cheng, Hamida Demirdache (eds.), MIT Working Papers in Linguistics, Vol. 13, MIT, Cambridge, MA.

Bresnan, Joan W. 1971. Sentence Stress and Syntactic Transformations. Language 47, 257-281. Bresnan, Joan W. 1972. Stress and Syntax: A Reply. Language 48, 326-342.

21 Another frequent misconception is the belief that since $\mathrm{N}$ constraints determine $\mathrm{N}$ ! distinct rankings, they also predict $\mathrm{N}$ ! distinct optimal forms and therefore at least $\mathrm{N}$ ! empirically distinct languages. The set of distinct optima does not follow from the number of constraints or rankings but from the conflicts among the constraints. This is easily seen by considering the case of $\mathrm{N}$ constraints that never conflict with each other. There still remain N! rankings but they all select the same optimal structure, namely the one that violate each constraint the least. The overall crosslinguistic typology in this case reduces to a single optimal form. 
Brody, Michael. 1990. Remarks on the Order of Elements in the Hungarian Focus Field. In Istvan Kenesei (ed.). Approaches to Hungarian. Structures and Arguments. Vol. 3. JATE, Szeged, pp. 95-121.

Brunetti, Lisa. 2003. A Unification of Focus. Ph.D. Dissertation. University of Firenze. Firenze.

Büring, Daniel. 2001. Let's Phrase it! Focus, Word Order, and Prosodic Phrasing in German Double Object Constructions. In Gereon Müller and Wolfgang Sternefeld (eds.), Competition in Syntax. Mouton de Gruyter, New York, NY, pp. 69-105.

Büring, Daniel. 2002. What Do Definites Do That Indefinites Definitely Don't?. in Caroline Féry, Wolfgang Sternefeld (eds.). Audiator Vox Sapientiae - A Festschrift for Arnim von Stechow. Studia Grammatica 52. Akademie Verlag, Berlin, pp.70-100.

Büring, Daniel. 2003. Focus Projection and Default Prominence. Ms. UCLA, Los Angeles, CA.

Büring, Daniel, and Rodrigo Gutíerrez-Bravo. 2002. Focus-related word order variation without the NSR. A Prosody-based crosslinguistic analysis. In Mac Bloscaidh, Séamas (ed.), Syntax at Santa Cruz 3, ICSC, Santa Cruz, CA, pp.41-58.

Büring, Daniel, and Katarina Hartmann. 1997. Doing the Right Thing. The Linguistic Review 14, $1-42$.

Calabrese, Andrea. 1982. Alcune ipotesi sulla struttura informazionale della frase in Italiano e sul suo rapporto con la struttura fonologica. Rivista di Grammatica Generativa 7.

Calabrese, Andrea. 1986. Pronomina - Some Properties of the Italian Pronominal System. In N. Fukui, T. Rapoport, E. Sagey (eds). MIT Working Papers in Linguistics, Vol. 8, MIT, Cambridge, MA, pp. 1-46.

Calabrese, Andrea. 1992. Some Informal Remarks on Focus and Logical Structures in Italian. In Kuno Susumi, Höskuldu Thrainsson (eds.), Harvard Working Papers in Linguistics, Vol. 1.

Cecchetto, Carlo. 1999. A Comparative Analysis of Left and Right Dislocation in Romance. Studia Linguistica 1, Vol. 53, 40-67.

Chen, Yiya. 2002. Accentual Lengthening of Monosyllabic Constituents in Bejing Mandarin. Ms. SUNY at Stony Brook, New York. Also at www.lpl.univ-aix.fr/sp2002/pdf/chen.pdf.

Chomsky, Noam. 1982. Some Concepts and Consequences of the Theory of Government and Binding. MIT Press, Cambridge, MA.

Chomsky, Noam. 1991. Some notes on economy of derivation and representation. In Robert Freidin (ed.), Principles and Parameters in Generative Grammar. MIT Press, Cambridge, MA, pp. 417-454.

Chomsky, Noam. 1992. A Minimalist Program for Linguistic Theory. MIT Occasional Papers in Linguistics. MIT, Cambridge, MA.

Chomsky, Noam. 1995. The Minimalist Program. MIT Press, Cambridge, MA.

Chomsky, Noam, and Morris Halle 1968. The Sound Pattern of English. Harper and Row, New York, NY.

Cinque, Guglielmo. 1993. A Null Theory of Phrase and Compound Stress. Linguistic Inquiry 24, 239-297.

Costa, João. 1998. Word Order Variation. A constraint-based approach. Ph.D. Dissertation, University of Leiden. Holland Academic Graphics, The Hague.

Costa, João. 2001. The Emergence of the Unmarked Word Order. In Geraldine Legendre, Jane Grimshaw, Sten Vikner (eds.), Optimality-Theoretic Syntax. MIT Press, Cambridge, MA, pp. 171-204.

Cruttenden, Alan. 1997. Intonation. Cambridge University Press, Cambridge.

Deevy, L. Patricia. 1995. An OT Analysis of Stress in Macedonian. In Jill Beckman, Laura Walsh Dickey, Suzanne Urbanczyk (eds.), University of Massachusetts Occasional Papers 18, UMASS, Amherst, MA, pp. 137-166.

Dehé, Nicole. To appear. The optimal placement of up ad ab - A comparison. In Journal of Comparative Germanic Linguistics.

Downing, Laura. 2002. Fitting focus phrasing into the Prosodic Hierarchy. SOAS Working Papers in Linguistics 12, 111-133. 
Downing, Laura. 2003. Stress, Tone and Focus in Chichewa and Xhosa. In Rose-Juliet Anyanwu (ed.). Stress and Tone - the African Experience. Frankfurter Afrikanistische Blätter 15. Rüdiger Köppe Verlag, Köln.

Elisabeth Engdahl, and Enric Vallduví. 1994. Information packaging and grammar architecture: A constraint-based approach. In Elisabeth Engdahl (ed.) Integrating information structure into constraint-based and categorial approaches. DYANA-2 Report R.1.3.B:39-79. ILLC, Amsterdam, pp.39-79.

Fery, Caroline. 2000. The Phonology of Focus in French. Ms., University of Potsdam. Later published as 'Focus in French' in Caroline Féry, Wolfgang Sternefeld (eds.). Audiator Vox Sapientiae - A Festschrift for Arnim von Stechow. Studia Grammatica 52. Akademie Verlag, Berlin, pp. 153-181.

Frascarelli, Mara. 2000. The Syntax-Phonology Interface in Focus and Topic Constructions in Italian. Kluwer Academic Publishers, Dordrecht.

Ghini, Mirco. 1993. $\Phi$-formation in Italian: a new proposal. Toronto Working Papers in Linguistics 12, 41-78. Department of Linguistics, University of Toronto, Toronto.

Grimshaw, Jane. 1993. Minimal Projections, Heads and Optimality. Ms. Rutgers University, New Brunswick, NJ.

Grimshaw, Jane. 1997. Projections, Heads and Optimality. Linguistic Inquiry 28, 373-422.

Grimshaw, Jane. 2001. Economy of Structure in OT. Ms., Rutgers University, New Brunswick, NJ.

Grimshaw, Jane and Vieri Samek-Lodovici. 1995. Optimal Subjects. In Jill Beckman, Laura Walsh Dickey, Suzanne Urbanczyk (eds.), University of Massachusetts Occasional Papers 18, UMASS, Amherst, MA, pp. 589-606.

Grimshaw, Jane, \& Samek-Lodovici, Vieri. 1998. Optimal Subjects and Subject Universals. In Pilar Barbosa, Danny Fox, Paul Hagstrom, Martha McGinnis, and David Pesetsky (eds.), Is the Best Good Enough. MIT Press, Cambridge, MA, pp. 193-220.

Gussenhoven, Carlo 1983. Focus, mode and the nucleus. Journal of Linguistics 19, 377-417.

Gussenhoven, Carlo 1984. On the grammar and semantics of sentence accents. Foris, Dordrecht.

Gutiérrez-Bravo, Rodrigo. 2000. Focus, Word Order Variation and Intonation in Spanish and English. In Caroline Wiltshire and Joaquim Camps (eds.) Romance Phonology and Variation. John Benjamins Publishing Company, Amsterdam, pp. 39-53.

Halle, Morris, and Jean-Roger Vergnaud. 1987. An Essay on Stress. MIT Press, Cambridge, MA. Halliday, M.A.K.. 1967. Notes on Transitivity and Theme in English - part 2. Journal of Linguistics 3, 199-244.

Hammonds, Michael. 1984. Constraining Metrical Theory: a Modular Theory of Rhythm and Destressing. Ph.D. Dissertation, University of California, Los Angeles, CA.

Hayes, Bruce. 1989. The Prosodic Hierarchy in Meter. In Paul Kiparsky and Gilbert Youmans (eds.), Rhythm and meter. Academic Press, Orlando, FL, pp. 201-260.

Hayes, Bruce. 1995. Metrical Stress Theory. The University of Chicago Press, Chicago, IL.

Hayes, Bruce, and Aditi Lahiri. 1991. Bengali Intonational Phonology. Natural Language and Linguistic Theory 9, 47-96.

Horvath, Julia. 1986. FOCUS in the Theory of Grammar and the Syntax of Hungarian. Foris, Dordrecht.

Jackendoff, Ray. 1972. Semantic Interpretation in Generative Grammar. MIT Press, Cambridge, MA.

Kayne, Richard 1994. The Antisymmetry of Syntax. Linguistic Inquiry Monograph 25. MIT Press, Cambridge, MA.

Kanerva, Jonni M. 1990a. Focus and Phrasing in Chichewa Phonology. Garland, New York, NY.

Kanerva, Jonni M. 1990b. Focus on Phonological Phrases in Chichewa. In Sharon Inkelas and Draga Zec (eds.), The Phonology-Syntax Connection. The University of Chicago Press, Chicago, IL, pp. 145-162. 
Keller, Frank, and Theodora Alexopoulou. 2001. Phonology competes with syntax: experimental evidence for the interaction of word order and accent placement in the realization of Information Structure. Cognition 79, 301-372.

Kiss, Katalin. 1981. Structural Relations in Hungarian, a 'Free' Word Order Language. Linguistic Inquiry 12, 185-213.

Ladd, Robert. 1980. The structure of intonational meaning: evidence from English. Indiana University Press, Bloomington.

Ladd, Robert. 1986. Intonational phrasing: the case for recursive prosodic structure. Phonology Yearbook 3, 311-140.

Ladd, Robert. 1996. Intonational Phonology. Cambridge University Press, Cambridge.

Ladd, Robert. 2001. Intonation. In Martin Haspelmath, Ekkehard König, Wulf Oesterreicher, and Wolfgang Raible. Language Typology and Language Universals. Walter de Gruyter, Berlin, pp. 1380-1390.

Laka, Itziar. 1990. Negation in Syntax: on the Nature of Functional Categories and Projections. Ph.D. Dissertation, MIT, Cambridge, MA.

Lambrecht, Knud. 1994. Information Structure and Sentence Form. Cambridge University Press, Cambridge.

Liberman, Mark, and Alan Prince. 1977. On Stress and Linguistics Rhythm. Linguistic Inquiry 8, 249-336.

May, Robert. 1985. Logical Form. MIT Press, Cambridge, MA.

McCarthy, John. 2002. A Thematic Guide to Optimality Theory. Cambridge University Press, Cambridge.

McCarthy, John, and Alan Prince. 1993. Generalized Alignment. Technical Report TR-7, Rutgers Center for Cognitive Science, Rutgers University, New Brunswick, NJ.

Müller, Gereon. 2001. Order Preservation, Parallel Movement, and the Emergence of the Unmarked. In Geraldine Legendre, Jane Grimshaw, Sten Vikner (eds.), Optimality-Theoretic Syntax. MIT Press, Cambridge, MA, pp. 279-314.

Nespor, Marina. 1990. On the Separation of Prosody and Rhythmic Phonology. In Sharon Inkelas, and Draga Zec (eds.), The Phonology Syntax Connection. University of Chicago Press, Chicago, IL, pp. 243-258.

Nespor, Marina, and Irene Vogel. 1986. Prosodic Phonology. Foris, Dordrecht.

Nespor, Marina, and Irene Vogel. 1989. On Clashes and Lapses. Phonology 6, 69-116.

Ordóñez, Francisco. 1997. Word Order and Clause Structure in Spanish and Other Romance Languages. Doctoral Dissertation, CUNY, New York, NY.

Pinto, Manuela. 1997. Licensing and Interpretation of Inverted Subjects in Italian. Ph.D. Dissertation, UIL-OTS, Utrecht Institute of Linguistics, Utrecht.

Prince, Alan. 1983. Relating to the Grid. Linguistic Inquiry 14, 19-100.

Prince, Alan. 2000. Comparative tableaux. Ms., Rutgers University, New Brunswick, NJ.

Prince, Alan and Paul Smolensky. 1993. Optimality: Constraint Interaction in Generative Grammar. Technical Report TR-2, Rutgers Center for Cognitive Science, Rutgers University, New Brunswick, NJ.

Reinhart, Tanya. 1995. Interface Strategies. OTS Working Papers, OTS-WP-TL-95-002, Utrecht University, Utrecht.

Rizzi, Luigi. 1990. Relativized Minimality. MIT Press, Cambridge, MA.

Rizzi, Luigi. 1997. The Fine Structure of the Left Periphery. In Liliane Haegemann (ed.), Elements of Grammar. Handbook of Generative Syntax. Kluwer, Dortrecht, pp. 281-337.

Rochemont, Michael S. 1986. Focus in Generative Grammar. John Benjamins Publishing Company, Philadelphia, PA.

Rochemont, Michael S., and Peter W. Culicover. 1990. English Focus Constructions and the Theory of Grammar. Cambridge University Press, Cambridge.

Saccon, Graziella. 1993. Postverbal Subjects. Ph.D. Dissertation, Harvard University. 
Samek-Lodovici, Vieri. 1996a. Constraints on Subjects. An Optimality Theoretic Analysis. Ph.D. Dissertation, Rutgers University, New Brunswick, NJ.

Samek-Lodovici, Vieri. 1996b. Structural Contrastive Focus in Italian, with and without Emphatic Stress. Ms. Konstanz University, Konstanz.

Samek-Lodovici, Vieri, and Alan Prince. 1999. Optima. Technical Report TR-57, Rutgers Center for Cognitive Science, Rutgers University, New Brunswick, NJ.

Samek-Lodovici, Vieri. 2001. Crosslinguistic Typologies in Optimality Theory. In Geraldine Legendre, Jane Grimshaw, Sten Vikner (eds.), Optimality-Theoretic Syntax. MIT Press, Cambridge, MA, pp. 315-354.

Schmerling, Susan F. 1976. Aspects of English Sentence Stress. University of Texas Press, Austin, TX.

Schwarzschild, Roger. 1999. Giveness, AvoidF and other Constraints on the Placement of Accent. Natural Language Semantics 7, 141-177.

Selkirk, Elisabeth. 1984. Phonology and Syntax: The Relation between Sound and Structure. MIT Press, Cambridge, MA.

Selkirk, Elisabeth. 1986. On derived domains in sentence phonology. Phonology Yearbook 3, 371-405.

Selkirk, Elisabeth. 1995. Sentence Prosody: Intonation, Stress, and Phrasing. In John A. Goldsmith (ed.), The Handbook of Phonological Theory. Blackwell, Cambridge, pp. 550-569.

Szendröi, Kriszta. 2001. Focus and the Syntax-Phonology Interface. Ph.D. Dissertation. University College London, London.

Szendröi, Kriszta. 2002. Stress-Focus Correspondence in Italian; Ms. ROA 547-1002, http://roa.rutgers.edu.

Truckenbrodt, Hubert. 1995. Phonological Phrases: their Relation to Syntax, Focus, and Prominence. Ph.D. Dissertation, MIT, Cambridge, MA.

Truckenbrodt, Hubert. 1997. Correspondence of Syntactic and Phonological Phrases. Ms. Rutgers University, New Brunswick, NJ.

Truckenbrodt, Hubert. 1998. Squeezing: the Syntax-Prosody Mapping Meets OT Syntax. Handout of talk at Linguistic-Lunch, MIT. Cambridge, MA..

Truckenbrodt, Hubert. 1999. On the Relation between Syntactic Phrases and Phonological Phrases. Linguistic Inquiry 30, 219-255.

Vallduví, Enric. 1991. The role of plasticity in the association of focus and prominence. ESCOL 7, 295-306.

Vallduví, Enric. 1992 The Informational Component. Garland, New York.

Vallduví, Enric. 1993 Detachment in Catalan and Information Packaging. Journal of Pragmatics 22, 573-601.

Vikner, Sten. 2001. $\mathrm{V}^{\mathrm{o}}$-to- $\mathrm{I}^{\mathrm{o}}$ Movement and $d o$-Insertion in Optimality Theory. In Geraldine Legendre, Jane Grimshaw, Sten Vikner (eds.), Optimality-Theoretic Syntax. MIT Press, Cambridge, MA, pp. 427-464.

Wiltshire, Caroline. 1998. Extending ALIGN constraints to new domains. Linguistics 36, Vol. 3, 423-467.

Zanuttini, Raffaella. 1991. Syntactic Properties of Sentential Negation. A Comparative Study of Romance Languages. Ph.D. Dissertation. University of Pennsylvania, Philadelphia, PA.

Zubizarreta, Marîa Luisa. 1994. On Some Prosodically Governed Syntactic Operations. In Guglielmo Cinque, Jan Koster, Jean-Yves Pollock, Luigi Rizzi, Raffaella Zanuttini (eds.), Paths Toward Universal Grammar. Studies in Honor of Richard S. Kayne. Georgetown University Press, Wash. DC, pp. 473-485.

Zubizarreta, Maria Luisa. 1998. Prosody, Focus, and Word Order. MIT-Press, Cambridge, MA.

August 2004 
Italian Department

University College London

Gower Street

WC1E 6BT, London

UK

<ucljvsl@ucl.ac.uk> 